\title{
TUD-1: synthesis and application of a versatile catalyst, carrier, material...
}

\author{
Selvedin Telalović, ${ }^{a}$ Anand Ramanathan, ${ }^{b}$ Guido Mul ${ }^{a}$ and Ulf Hanefeld ${ }^{* a}$ \\ Received 2nd March 2009, Accepted 30th July 2009 \\ First published as an Advance Article on the web 28th August 2009 \\ DOI: $10.1039 / b 904193 a$
}

The three-dimensional sponge-like mesoporous material TUD-1 is straightforward to prepare. Its synthesis can readily be modified to introduce metals into the framework of TUD-1, imparting many different catalytic activities. M-TUD-1 catalysts have proven to be very active, unlimited by diffusion and very stable. By combining two metals into one TUD-1 catalyst, synergy between Lewis and Brønsted acid sites could be induced; incorporation of zeolites similarly gave rise to synergy. In addition to successful applications in redox-, acid- and photo-catalysis TUD-1 proved to be an excellent carrier material for catalysts, enabling new applications. TUD-1 was used as a contrast agent and drug delivery system, indicating that this material is but at the beginning of its potential applications.

\section{Introduction}

Mesoporous silicates are versatile materials with many, tuneable properties. Some twenty years ago the first reports on MCM-41 appeared giving the field of these multifunctional materials a major impulse and since then many differently structured mesoporous silicates have been described. ${ }^{1}$ In 2001 TUD-1, a mesoporous silicate first synthesised at the Technische Universiteit Delft, was described by Jansen et $a l^{2}{ }^{2}$ Unlike most other mesoporous materials TUD-1 is straightforward to prepare. It has a sponge-like pore structure, i.e. the pore system is

${ }^{a}$ Gebouw voor Scheikunde, Technische Universiteit Delft, Julianalaan 136, 2628 BL Delft, The Netherlands. E-mail: u.hanefeld@tudelft.nl; Fax: +31 15278 1415; Tel: +31 152789304

${ }^{b}$ Department of Chemistry, University College of Engineering, Tindivanam (Anna University, Chennai), Saram-604307, Tamil Nadu, India. E-mail: anand_ncl@yahoo.com three-dimensional and irregular. This allows for fast diffusion into and out of TUD-1, making the material an ideal starting point for catalyst development. Now, almost a decade after its first description, the catalysis with and chemistry of TUD-1 is well-developed. This manuscript aims at bringing together all the different applications of TUD-1 and the underlying syntheses, discussing past achievements and the potential that TUD-1 holds for the future.

\section{Synthesis and characterisation of TUD-1}

One of the key features of TUD-1 is its straightforward synthesis. It is based on the sol-gel methodology. As the silicon source for the siliceous material tetraethyl orthosilicate (TEOS) is the starting material of choice. Unlike in the preparation of many other mesoporous materials no surfactants are used in order to achieve a regular pore structure. ${ }^{2,3}$ Instead either triethanolamine $\left(\mathrm{TEAH}_{3}\right)$ or tetraethyleneglycol (TEG) are employed to chelate

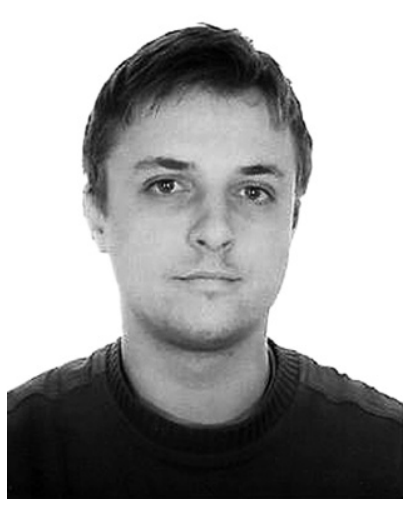

Selvedin Telalovic obtained his master degree in chemical engineering from the Technische Universiteit Delft in 2005. In the same year he received a Mozaïk fellowship from De Nederlandse Organisatie voor Wetenschappelijk Onderzoek (NWO) for a research proposal in the area of heterogeneous catalysis.
Selvedin Telalović

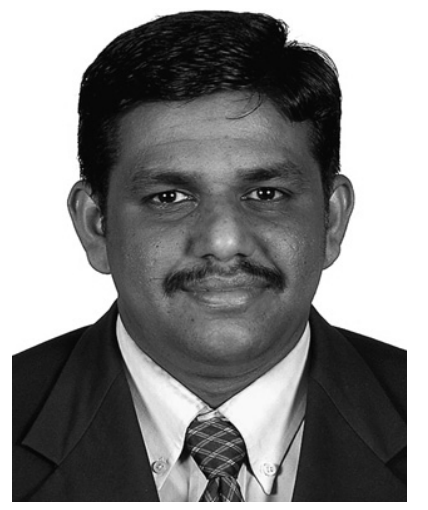

Anand Ramanathan
$R$. Anand received his $P h D$ in Chemistry from the University of Pune, India in 2002 under the supervision of $\mathrm{Dr}$ B. S. Rao. After two years postdoctoral research at TUDelft under supervision of Prof. Ulf Hanefeld and Prof. Thomas Maschmeyer, he moved on to South Korea and Germany to carry out postdoctoral research in the area of mesoporous materials. He joined the National Institute of Technology, Trichirappalli, India as lecturer and is presently working as Assistant Professor at Anna University (University College of Engineering, Tindivanam), Chennai, India. His main research interests are heterogeneous catalysis, synthesis and characterization of porous materials and oxidation catalysts. 
the silicon. At the same time these chelators are crucial to achieve a porous structure. $\mathrm{TEAH}_{3}$ will form an atrane with silicon, silatrane. ${ }^{4,5}$ The initial silatrane can dimerise, trimerise etc. and thus function as a template and as the silicate source at the same time (Scheme 1). The monomers, dimers and oligomers are in equilibrium and they are the source of monomeric orthosilicate which forms the growing structured silicate. Thus the atrane needs to be hydrolysed to release the silicate monomer which then condenses. Recently, chelators were employed for a different synthesis of mesoporous materials. In this "atrane route" $\mathrm{TEAH}_{3}$ is also utilised for the formation of atranes. ${ }^{6-9}$ However, this occurs in the presence of surfactants to determine the structure of the mesoporous material. In studies on the atrane route it was demonstrated, that before the actual condensation of the metal oxides into mesoporous materials the atrane is monomeric. ${ }^{8}$ Very recently an expansion of the "atrane route" was described in which no surfactant was added. The resulting material denoted UVM-11 essentially is TUD-1. ${ }^{10}$ It basically reconfirms the surfactant-free and unique synthesis of TUD-1.

Once TEOS, $\mathrm{TEAH}_{3}$ and water are mixed a homogeneous solution results. Aging leads to the gel, which is dried at higher temperatures. The resulting solid is thus far not fully condensed nor does it yet have the typical TUD-1 structure. ${ }^{2,11}$ It is ground and then hydrothermally treated in an autoclave, and further condensation releases water and alcohols. After the hydrothermal treatment the material has the typical TUD-1 structure (Fig. 1 and 2). The $\mathrm{TEAH}_{3}$ is commonly removed by calcination but can also be extracted (Scheme 1). The resulting material has pore diameters between 5 and $20 \mathrm{~nm}$, surface areas between 500 and $1000 \mathrm{~m}^{2} / \mathrm{g}$ and pore volumes of 0.6 to $1.7 \mathrm{~cm}^{3} / \mathrm{g}$.

Next to the synthesis via the atranes the TEG route to TUD-1 was developed (Scheme 1). In this case the neutral TEG complexes both silicate and other metal oxides. In principle similar results to the atrane approach with $\mathrm{TEAH}_{3}$ are obtained. A significant advantage of TEG is that higher metal loadings in siliceous TUD-1 can be achieved.
This emphasises that TUD-1 is, from a synthetic point of view, a sol-gel; as might be expected from a material prepared via the sol-gel methodology. Its unique characteristics are the mesoporous, three-dimensional, sponge-like structure (Fig. 2 and 3), combined with high stability and the possibility to incorporate countless metals into the framework. All this is achieved with a very straightforward and environmentally benign synthesis. Thus TUD-1 distinguishes itself from all other mesoporous materials prepared with the aid of a surfactant, while at the same time displays much higher stability than sol-gels and xero-gels. ${ }^{12}$ Actually, a typical characteristic of xero-gels is their partially collapsed pore structure due to capillary forces during the drying process. This is clearly not the case for TUD-1 (Fig. 2). ${ }^{12,13}$

The time of the hydrothermal treatment has a strong influence on the character of TUD-1. Short treatment yields TUD-1 with small pores of approx. $5 \mathrm{~nm}$, while prolonged treatment leads to larger pores. At the same time the surface area drops with extended heating and the wall thickness increases (Fig. 1). ${ }^{2}$ This synthesis can also be performed with other metal oxides, for instance to produce $\mathrm{Al}_{2} \mathrm{O}_{3}$ with TUD-1 structure. ${ }^{14-16}$ These processes have been scaled up to ton level and are very robust. ${ }^{17}$ Equally the materials are very robust and show long life times in catalytic conversions. ${ }^{18,19}$

The structure of TUD-1 can be further refined by adding tetraethyl ammonium hydroxide (TEAOH) to the initial reaction mixture. ${ }^{2}$ TEAOH induces microporosity into TUD-1 ensuring that a continuous scale of pores, ranging from $20 \mathrm{~nm}$ down to less than $1 \mathrm{~nm}$ is formed. In most TUD-1 syntheses TEAOH forms part of the reaction mixture, it is however, not an essential part.

The synthesis of siliceous or metal oxide based TUD-1 can be further expanded by adding other metal oxides as salts or preferably as alcoholates, to the reaction mixture. ${ }^{11,19}$ In this manner many different metal containing siliceous TUD-1 have been prepared, denoted as M-TUD-1. Just as in the synthesis of purely siliceous TUD-1 the TEOS and the metal alcoholates lead to the formation of atranes if $\mathrm{TEAH}_{3}$ is employed, or to TEG

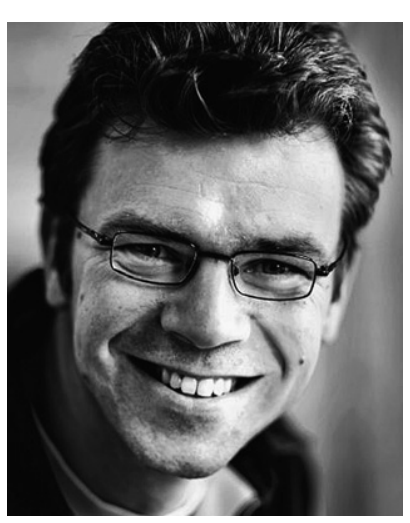

Guido Mul
Guido Mul obtained his M.Sc. degree from Utrecht University and his PhD degree from the Technische Universiteit Delft. Following, he obtained a postdoctoral position at SRI-International in California, USA (1997-1999). He then returned to Delft as an assistant professor to elucidate the mechanism of $\left(\mathrm{N}_{2} \mathrm{O}\right.$ induced) heterogeneous catalytic reactions and to evaluate spectroscopies (ATR, Raman) for analyses of liquid phase catalytic processes. He was promoted to associate professor in January 2007. His current research interests include optimization of photocatalysts and reactor concepts for selective oxidation reactions (gas and liquid phase) and $\mathrm{CO}_{2}$ activation to hydrocarbons.

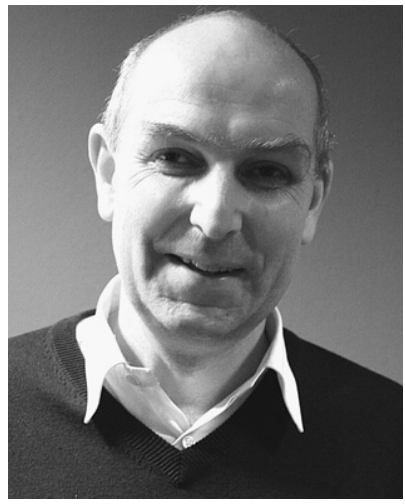

Ulf Hanefeld
In 1993 Ulf Hanefeld received his PhD from the Georg-AugustUniversität zu Göttingen, having performed research both in Göttingen (H. Laatsch) and Seattle (H. G. Floss). After postdoctoral years with $C . W$. Rees (Imperial College London), J. Staunton (Cambridge) and J. J. Heijnen and A. J. J. Straathof (TUDelft), he received a fellowship from the Royal Netherlands Academy of Arts and Sciences (KNAW). His research at the Technische Universiteit Delft focuses on enzymes and heterogeneous catalysis in organic synthesis. 
Optional: metal-salt or preferably metal-alkoholate + water

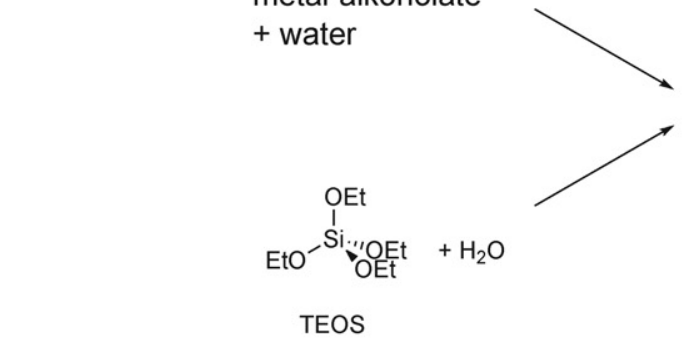

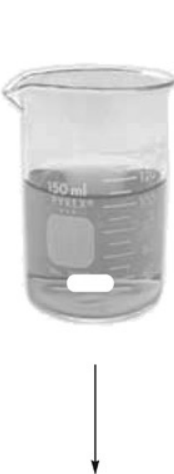<smiles>OCCOCCOCCOCCN(CCO)CCO</smiles><smiles>CCN(CC)O[Os]O</smiles>

TEAOH

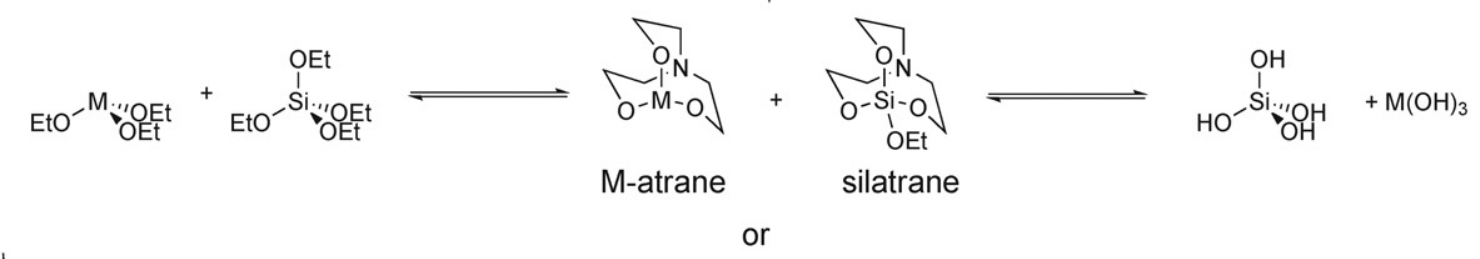

TEG complexes of $\mathrm{Si}$ and the metal

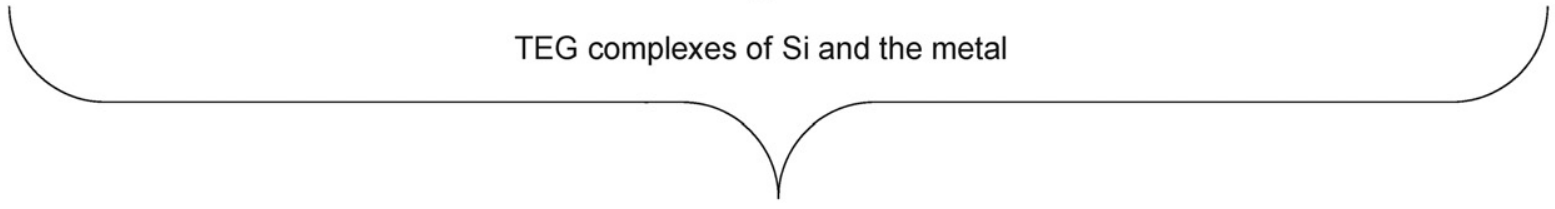

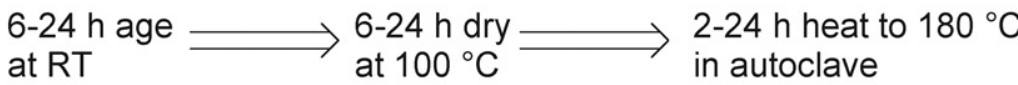

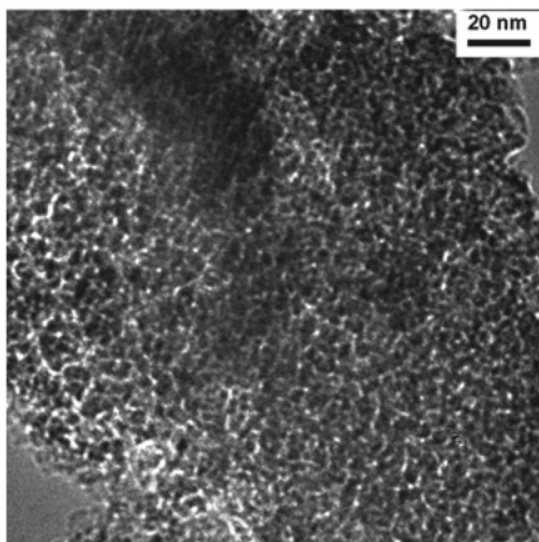

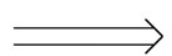

Calcine in stream of air at $600{ }^{\circ} \mathrm{C}\left(1{ }^{\circ} \mathrm{C} / \mathrm{min}\right)$ or Soxhlet extraction with ethanol 3 days.

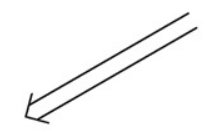

\section{TUD-1}

Scheme 1 The synthesis of mesoporous TUD-1 and M-TUD-1 is straightforward.

complexes if TEG is used (Scheme 1). The atranes ensure that the metal oxide becomes available as a single metal species, thus ensuring its isolated incorporation into the silica framework. ${ }^{8}$ Metal oxide particles are not formed, since this is prevented by the metal atranes or TEG complexes. Indeed for $\mathrm{Si} / \mathrm{M}$ ratios of 50 all metal is framework incorporated and isolated and no metal oxide nanoparticles or bulk particles were detected. For many metals this is also true for ratios as high as 25 . If the metal concentration is further increased, metal oxide nanoparticles are observed, and with a further increase of the metal concentration the bulk metal oxide particles become part of the structure (Table 1). The appearance of metal particles is combined with a drop in pore volume, indicating that the metal oxide crystals are present in the pores of TUD-1. Another important feature of the M-TUD-1 synthesis is its high predictability. The ratio of
$\mathrm{Si} / \mathrm{M}$ in the synthesis mixture is virtually unchanged in the final M-TUD-1 (Table 1).

If truly high metal concentrations in siliceous TUD-1 need to be achieved, $\mathrm{TEAH}_{3}$ has to be replaced by TEG. In the synthesis of Al-TUD-1 with a Si/Al ratio of 4, TEG was used instead of $\mathrm{TEAH}_{3}$. This enabled the synthesis of aluminium rich Al-TUD-1 with more than $40 \%$ of the Al tetrahedrally incorporated, the other $\mathrm{Al}$ atoms were incorporated via penta-coordination or hexa-coordination. No $\mathrm{Al}_{2} \mathrm{O}_{3}$ particles could be detected. ${ }^{20,21}$ This is a special feature of the TUD-1 synthesis and it allows the preparation of M-TUD-1 with low $\mathrm{Si} / \mathrm{M}$ ratios via direct synthesis. In many other materials it is necessary to graft the metal onto the siliceous material in a post synthesis step. ${ }^{22,23}$

The structure of TUD-1 as a three dimensional mesoporous material was unambiguously demonstrated by 3-D TEM 


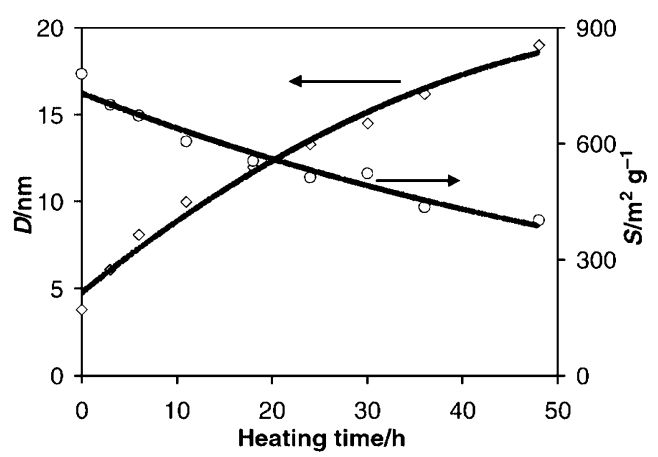

Fig. 1 Variations of the hydrothermal treatment lead to significant changes in the mesopore diameter $(D)$ and the mesopore surface area $(S)$; allowing fine-tuning of the structure of TUD-1. Reproduced by permission of the Royal Society of Chemistry from ref. 2.

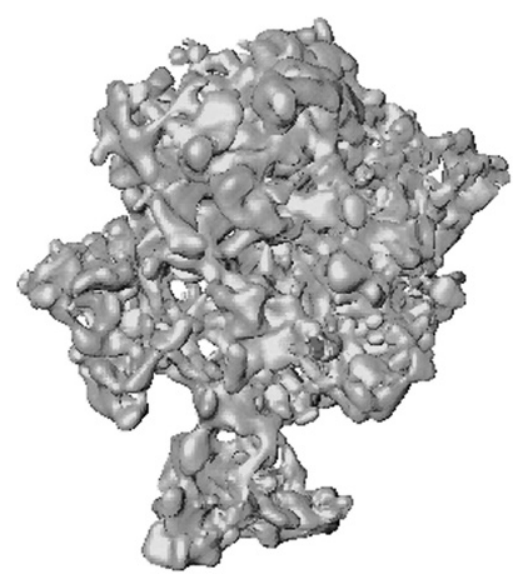

Fig. 2 The huge pore volume of TUD-1 is clearly visible in this 3-D TEM. Reprinted from ref. 24, Copyright (2005) with permission from Elsevier.

studies. ${ }^{24}$ Fig. 2 depicts the pore volume, i.e. the void space in TUD-1. The sponge-like character of TUD-1 with irregular interconnected pores of different diameters is clearly visible. XRD, TEM, IR, UV, XPS, MAS-NMR and $\mathrm{N}_{2}$-sorption studies were employed to confirm these structural features in TUD-1 and all the M-TUD-1s. ${ }^{25}$ Fig. 3 gives typical examples for all analytical techniques. Thus almost ten years after its first synthesis TUD-1 is a material that can easily be synthesised via a straightforward and robust synthesis. The properties of TUD-1 can without difficulty be varied and many different properties can be imparted by the judicious choice of the metal added, its amount and the duration of the hydrothermal treatment. The resulting material is particularly stable and its production is scalable for industrial needs. ${ }^{17,18,26,27}$ In a recent detailed contribution the large scale synthesis of Al-TUD-1 was described and the environmental and cost advantages of TUD-1 over other mesoporous materials were demonstrated. Starting from low cost silica gel and aluminium hydroxide, rather than TEOS and aluminium(III)isopropoxide, significantly reduced costs and the recycling of the complexing agents $\mathrm{TEAH}_{3}$ and TEG limited costs and reduced the environmental burden of the synthesis of TUD-1. The laboratory synthesis of TUD-1 is already particularly efficient but this industrial preparation TUD-1 is especially favourable. ${ }^{27}$

Overall, TUD-1 is thus a distinct material with a straightforward, highly reproducible synthesis that allows for many modifications and applications, both in the laboratory and in industry.

\section{Catalysis with TUD-1}

Mesoporous materials are such versatile substances as they enable countless new catalytic reactions, expanding the narrow application field of zeolites. ${ }^{28}$ TUD-1, with its three-dimensional sponge-like structure is ideal for catalysis, since it facilitates diffusion-free processes, only limited by the activity of the catalyst itself. Indeed, TUD-1, and in particular M-TUD-1, has proven to be a very versatile and stable catalyst.

To impart catalytic activity to mesoporous materials it is either possible to utilise the intrinsic acidity or alkaline character of a purely siliceous or $\mathrm{Al}_{2} \mathrm{O}_{3}$ based material. The strategy to introduce a metal oxide into the framework of the siliceous, mesoporous material was and is much more successful. Here, another advantage of TUD-1 is revealed. As explained above (Section 2), the incorporation of isolated metal atoms into the TUD-1 framework is straightforward and does not require any post synthesis modifications of TUD-1. Equally the introduction of metal oxide nanoparticles and larger clusters can be achieved during the synthesis. Thus, acidic and redox active TUD-1 catalysts are readily prepared.

\subsection{Reactions catalysed by acidic M-TUD-1}

3.1.1. Fe-TUD-1 as a catalyst of Friedel-Crafts alkylations. Friedel-Crafts alkylations are acid-catalysed processes that are applied on an industrial scale. While the reaction is catalysed by an acid such as $\mathrm{FeCl}_{3}$, this acid is typically hydrolysed at the end of the reaction and not recycled, causing much waste. Replacing these homogeneous catalysts with heterogeneous catalysts has always been a target of heterogeneous catalysis. By preparing FeTUD-1 with a Si/Fe ratio of 10 to 100 both Fe-TUD-1 with only framework incorporated Fe and Fe-TUD-1 with iron oxide nanoparticles distributed throughout the pore system of TUD-1, could be prepared (Table 1). ${ }^{29,30}$

Both types of Fe-TUD-1, with and without nanoparticles, catalysed the benzylation of benzene (Scheme 2); however, the Fe-TUD-1 with high iron content and thus the highest concentration of $\mathrm{Fe}_{2} \mathrm{O}_{3}$ nanoparticles is the most active catalyst. The Fe-TUD-1 catalysts outperformed Ga-TUD-1, Sn-TUD-1, Ti-TUD-1 as well as Fe-HMS, Fe-MCM-41 and Fe-MFI. Hot filtration studies did however; reveal a weakness of the Fe-TUD-1 catalysts. While no activity leached, almost half of the iron was washed out of the material, casting doubt on its recyclability. None the less in the comparison of the catalytic activity (TOF) of different meso- and microporous catalysts such as Fe-MCM-41, ${ }^{31} \mathrm{Fe}-\mathrm{HMS}^{32}$ and Fe-MFI ${ }^{33}$ with Fe-TUD1, Fe-TUD-1 showed that irrespective of the Fe loading, it was more active than other Fe-containing micro- or mesoporous materials. This can be attributed again to the 3-dimensional, mesoporous structure which allows higher accessibility of the 


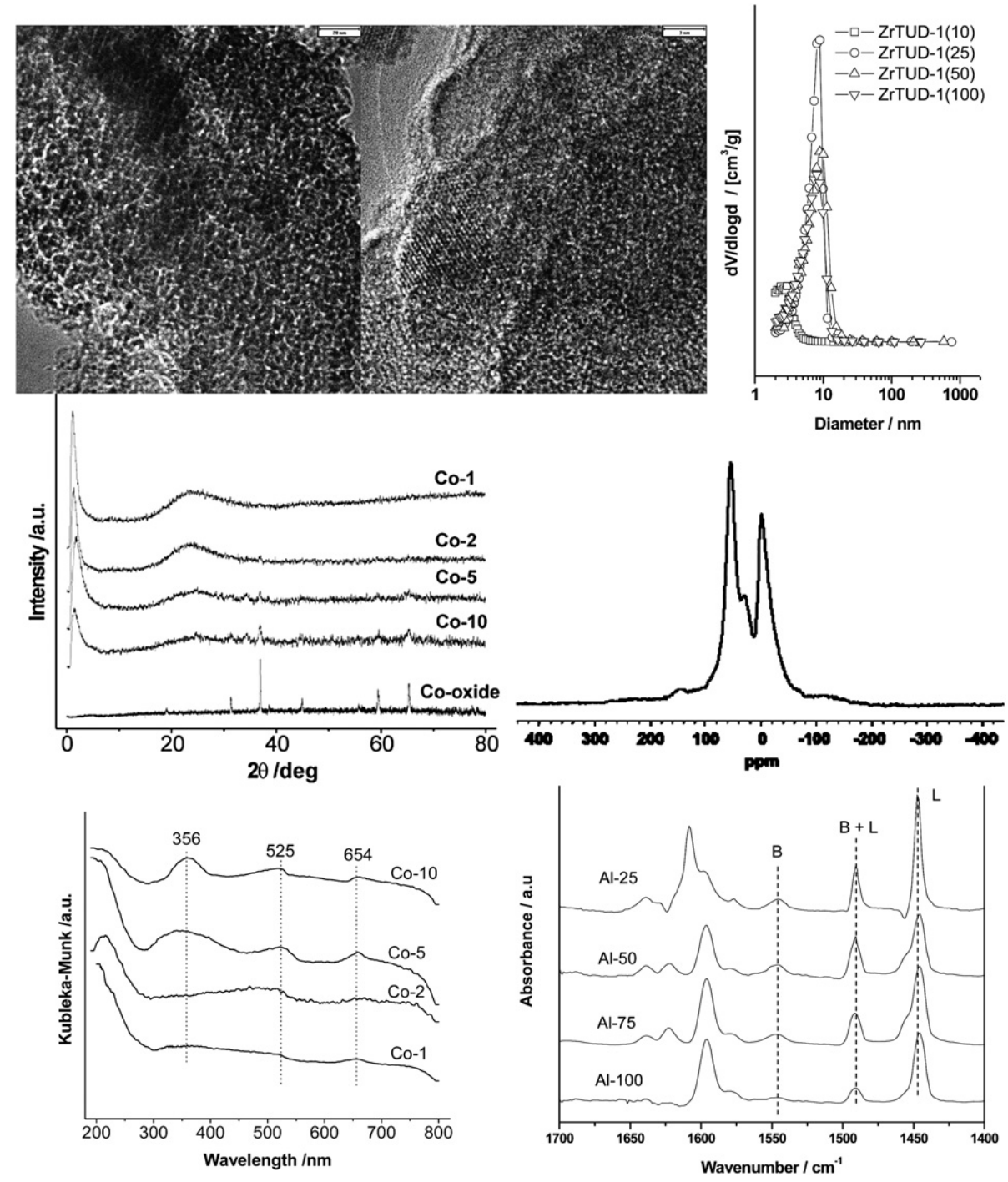

Fig. 3 Top left: HR-TEM of Zr-TUD-1 with Si/Zr = 25, the bar represents $20 \mathrm{~nm}$, reproduced with permission from ref. 43. Copyright 2008, WileyVCH Verlag GmbH\&Co. KGaA. Top middle: HR-TEM of $\mathrm{Zr}$-TUD-1 with $\mathrm{Si} / \mathrm{Zr}=10$, the bar represents $3 \mathrm{~nm}$, $\mathrm{ZrO}_{2}$ crystals are visible, reproduced with permission from ref. 43. Copyright 2008, Wiley-VCH Verlag GmbH\&Co. KGaA. Top right: pore size distribution of Zr-TUD-1 samples with Si/Zr ratios of 100, 50, 25 and 10 as determined by $\mathrm{N}_{2}$ adsorption and desorption isotherms, reproduced with permission from ref. 43 . Copyright 2008 , WileyVCH Verlag GmbH\&Co. KGaA. Middle left: XRD patterns of Co-TUD-1 samples with Si/Co ratios of 100 (1), 50 (2), 20 (5) and 10 (10) as well as $\mathrm{Co}_{3} \mathrm{O}_{4}$, reproduced with permission from ref. 59. Copyright 2006, Wiley-VCH Verlag GmbH\&Co. KGaA. Middle right: MAS-NMR of ${ }^{27} \mathrm{Al}$ in Al-TUD-1 with Si/Al = 4, reproduced with permission from ref. 20. Copyright 2004, Wiley-VCH Verlag GmbH\&Co. KGaA. Bottom left: UV/Vis spectra of Co-TUD-1 samples with Si/Co ratios of 100 (1), 50 (2), 20 (5) and 10 (10), reproduced with permission from ref. 59. Copyright 2006, Wiley-VCH Verlag GmbH\&Co. KGaA. Bottom right: FT-IR difference spectra of Al-TUD-1 samples with Si/Al ratios of 25, 50,75 and 100 after pyridine desorption at $200{ }^{\circ} \mathrm{C}$. Reprinted from ref. 35. Copyright (2006) with permission from Elsevier.

substrates. This also holds when comparing Fe-TUD-1 with Al-SBA-15. ${ }^{34}$

3.1.2. Al-TUD-1 as a versatile catalyst. Al-TUD-1 has been synthesised with many different $\mathrm{Si} / \mathrm{Al}$ ratios. At low aluminium concentrations $\mathrm{TEAH}_{3}$ is the chelating reagent of choice, at high aluminium concentrations, however, TEG had to be used as $\mathrm{TEAH}_{3}$ proved difficult to remove at a Si/Al below 10 . Remarkably all the aluminium was framework incorporated even at these high aluminium concentrations (Table 1). When the acidity of Al-TUD-1 was studied, it was noted that with increasing $\mathrm{Si} / \mathrm{Al}$ ratio the total acidity dropped but the acid strength increased-similar to what has been observed in zeolites.

Al-TUD-1s with a Si/Al of 3.5 and 4.85 were compared with a HY zeolite for the catalytic degradation of high density polyethylene and proved to have higher activity and stability than the zeolite. The mesoporous structure of Al-TUD-1 ensures diffusion-free access to the catalytic site, while this is not the case in the zeolite and equally coking is less of an issue in the wide pores of this material. ${ }^{21}$

The true value of Al-TUD-1 is revealed in the Friedel-Crafts alkylation of phenol. ${ }^{35}$ Utilising methyl tert-butyl ether (MTBE) or tert-butyl alcohol (TBA) as an alkylating reagent phenol could 


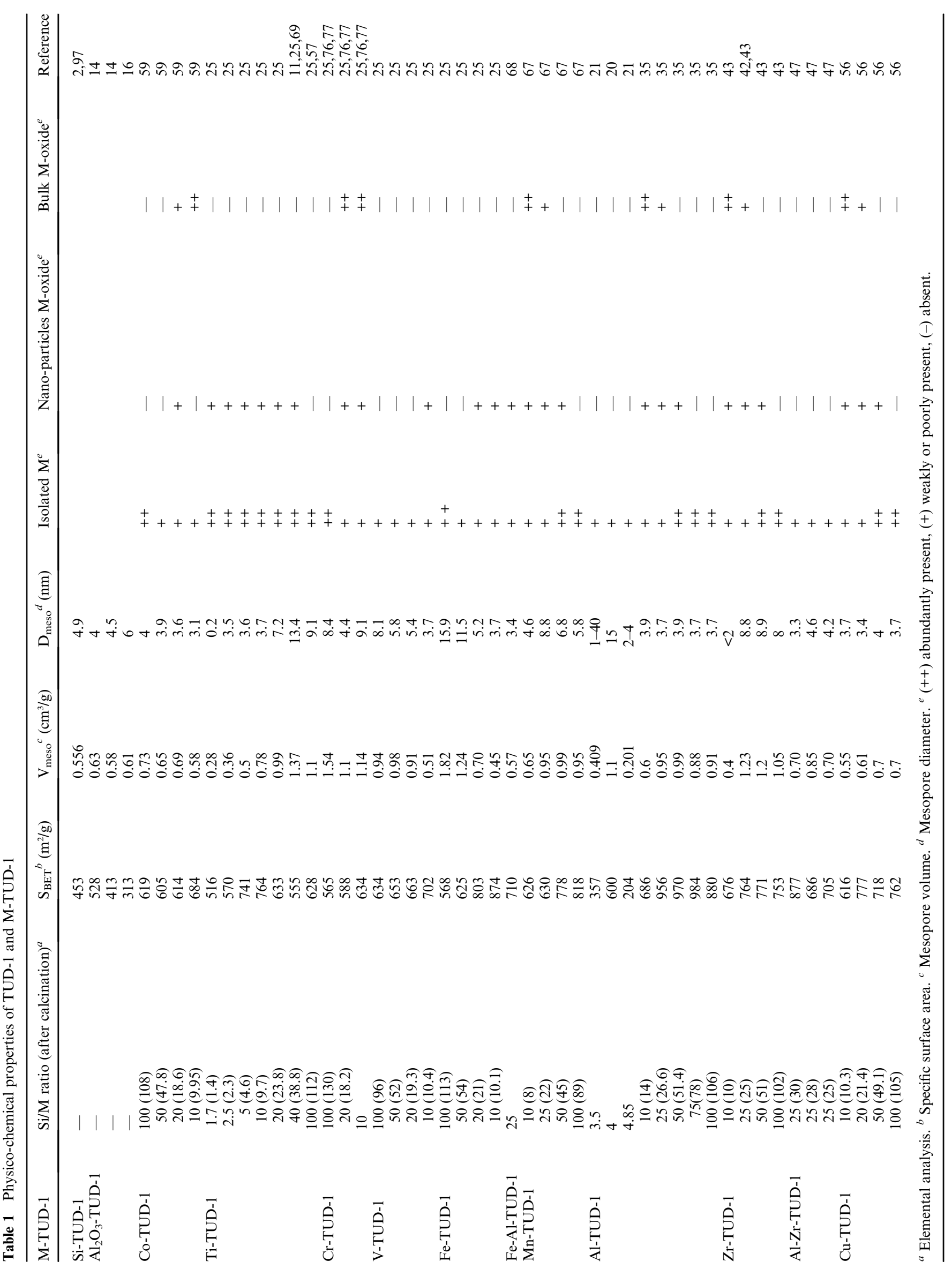


<smiles>ClCc1ccccc1</smiles>
10:1 $100 \%$ conversion in $<2 \mathrm{~min}$
Fe-TUD-1, reflux

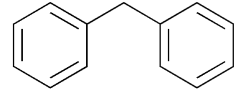

Scheme 2 Fe-TUD-1 with $\mathrm{Si} / \mathrm{Fe}=10$ is an excellent catalyst for the benzylation of benzene.

be alkylated both in the gas phase and in the liquid phase (Scheme 3). The conversion is directly dependent on the ratio of phenol to alkylating reagent, an excess of it leading to 2,4-ditert-butylphenol as main product in the liquid phase, while in the gas phase 4-tert-butylphenol always remains the dominant product (Fig. 4). Similar selectivity towards the 2,4-di-tertbutylphenol in the liquid phase was recently described for a tungsten catalyst. However, the material was not tested in the gas phase. ${ }^{36}$ In the gas phase reaction Al-TUD-1 with $\mathrm{Si} / \mathrm{Al}$ of 25 proved to be the best catalyst, it was stable over a period of $10 \mathrm{~h}$ (Fig. 5) and even when the weight hourly space velocity (WHSV) was increased to $4 \mathrm{~h}^{-1}$ conversions were unaltered at $70 \%$ (phenol/TBA = 2). This is strong evidence for the high stability and for the diffusion free character of this catalyst system (Fig. 6) also when comparing with Al-MCM-41, Al-MCM-48 and AlSBA-15. ${ }^{37-39}$ Al-MCM-48 and Al-MCM-41 gave 59\% and 36\% conversion of phenol respectively with $79.8 \%$ and $83.3 \%$ selectivity towards 4-tert-butylphenol $\left(175^{\circ} \mathrm{C}\right.$; WHSV $=4.8 \mathrm{~h}^{-1}$; TOS $=1.5 \mathrm{~h}$; TBA:phenol $=2: 1) .{ }^{38}$ Under similar reaction conditions $\left(175{ }^{\circ} \mathrm{C}\right.$; WHSV $=1 \mathrm{~h}^{-1}$; TOS $=2 \mathrm{~h}$; TBA:phenol $\left.=2: 1\right)$, Al-TUD-1 showed 70\% phenol conversion with $77 \%$ 4-tertbutylphenol selectivity. ${ }^{35}$

3.1.3. Zr-TUD-1 as a Lewis-acidic catalyst. Zirconium in its oxidation state $\mathrm{Zr}(\mathrm{IV})$ is a tetrahedrally coordinated metal which is purely Lewis acidic and unlike aluminium or iron, does not impart Brønsted acidity. ${ }^{40,41}$ Consequently the Zr-TUD-1 catalysts that only contain framework incorporated zirconium should be the ideal heterogeneous Lewis acid. When tested in the Lewis-acid catalysed Meerwein-Ponndorf-Verley reduction Zr-TUD-1 catalysed the reduction of sterically very demanding steroids such as 5 $\alpha$-cholestan-3-one to 5 $\alpha$-cholestan-3-ol, proving that the mesoporous structure enabled the reduction of large molecules. ${ }^{42}$ In the reduction of 4-tert-butyl-cyclohexanone (Scheme 4) the solvent dependence of the reaction was demonstrated and Zr-TUD-1 could be recycled without loss of activity (Fig. 7). ${ }^{43}$

Zr-TUD-1 displayed great stability in the Prins reaction, as demonstrated in the cyclisation of citronellal to isopulegol (Scheme 5). Even after five cycles virtually no loss of activity was observed and after calcination the initial activity was retained. Furthermore, hot filtration studies proved that no metal leached from the catalyst. When comparing Zr-TUD-1s with different $\mathrm{Si} / \mathrm{Zr}$ ratios it was again demonstrated that no diffusion limitation occurs (Fig. 8); the material with the highest $\mathrm{Si} / \mathrm{Zr}$ has by far the highest TOF. ${ }^{43}$

In a recent further development of the $\mathrm{Zr}(\mathrm{IV})$ catalysed Prins reaction, bifunctional catalysts have been described. These allow for the very efficient Prins reaction with for instance Zr-beta or Ir-beta and a subsequent reduction in the same pot. Thus a two step one pot synthesis of menthol was created. ${ }^{44-46}$

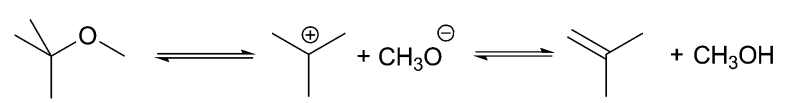<smiles>C=C(C)CCC(C)(C)c1ccccc1O</smiles><smiles>CC(C)=CC[C@H]1C=C(O)C=CC1(C)C(C)(C)C</smiles>
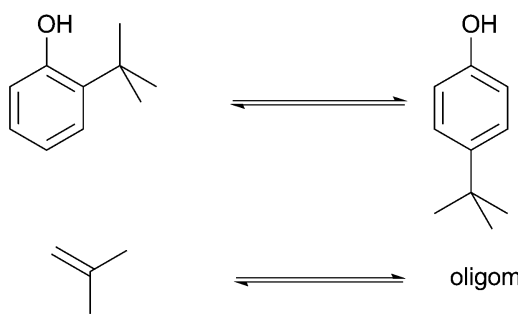

$\rightleftharpoons$ oligomers

Scheme 3 The Friedel-Crafts alkylation of phenol is an equilibrium reaction with four potential products, $o$ - and $p$-tert-butylphenol, as well as 2,4- and 2,6-di-tert-butylphenol.

3.1.4. Is there synergy in bimetallic Al-Zr-TUD-1?. Zr-TUD$1^{43}$ is a purely Lewis acidic material while Al-TUD-1 displays both types of acidity, Lewis and Brønsted. ${ }^{35}$ The combination of both metals in one catalyst would thus enable the tuning of the ratio of Lewis acid sites to Brønsted acid sites. This would allow studying the existence of synergy between the two types of acid sites; in particular, since the bimetallic Al-Zr-TUD-1 could be compared with Al-TUD-1 or Zr-TUD-1 with the same overall metal concentration. Thus Al-Zr-TUD-1 with a Si/M ratio of 25 and $\mathrm{Al} / \mathrm{Zr}$ ratios of $1: 3,2: 2$ and $3: 1$ were prepared. Pyridine desorption monitoring by IR spectroscopy clearly revealed an altered ratio of Brønsted to Lewis acidity. Brønsted $\left(1547 \mathrm{~cm}^{-1}\right)$ and Lewis acidity (Al: $1456 \mathrm{~cm}^{-1}, \mathrm{Zr}: 1448 \mathrm{~cm}^{-1}$; Fig. 9) could be distinguished and with an increase of $\mathrm{Zr}$ the signal for the Lewis acidic site due to $\mathrm{Al}$ decreases, as does that for Brønsted acidity. The ratio Brønsted/Lewis acidity decreases from approx. 1.1 for $\mathrm{Al} / \mathrm{Zr}=3: 1$ and $\mathrm{Al} / \mathrm{Zr}=2: 2$ to 0.7 for $\mathrm{Al} / \mathrm{Zr}=1: 3$. Thus a range of TUD-1 catalysts with either $\mathrm{Al}$ or $\mathrm{Zr}$ or mixtures thereof was available to study the influence of Brønsted acid sites on Lewis acid sites and vice versa. ${ }^{47}$ Earlier, theoretical studies on the synergy between Brønsted and Lewis acid sites had indicated that this synergy should exist. ${ }^{48}$ Indeed, the first experimental evidence had been presented for a Ce-Al-MCM-41. ${ }^{49}$

When Al-Zr-TUD-1 was employed in the Prins reaction (Scheme 5) the synergy between the Brønsted acid sites and the Lewis acid sites become obvious. This reaction can actually be catalysed by both Lewis and Brønsted acidic catalysts. Pure 

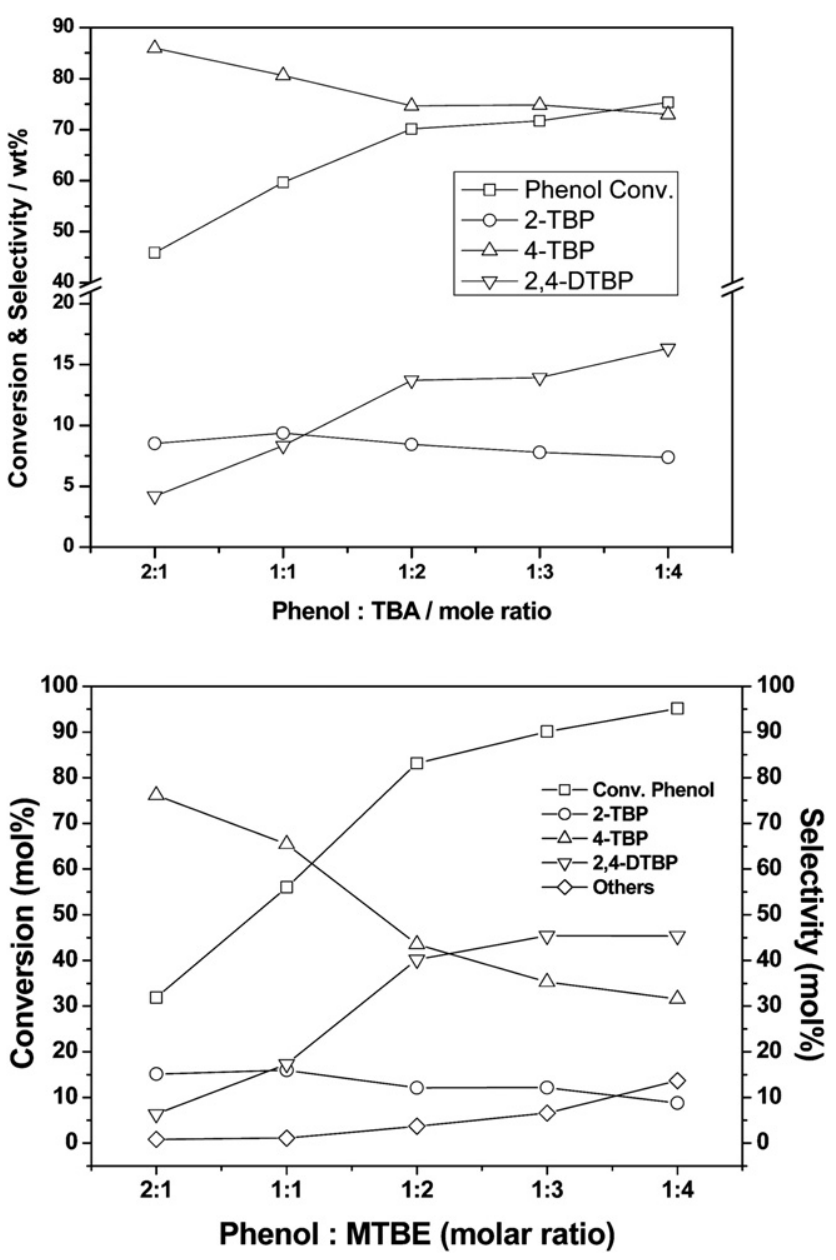

Fig. 4 Effect of phenol to alkylating reagent ratio in Al-TUD-1 Si/Al = 25 catalysed reaction. Top: gas phase reaction, WHSV of $1 \mathrm{~h}^{-1}$ at $175^{\circ} \mathrm{C}$. Bottom: liquid phase reaction, $150{ }^{\circ} \mathrm{C}, 0.2 \mathrm{~g}$ catalyst, 2.0 g reactants, $20 \mathrm{ml}$ cyclohexane, $4 \mathrm{~h}$. Reprinted from ref. 35. Copyright (2006) with permission from Elsevier.

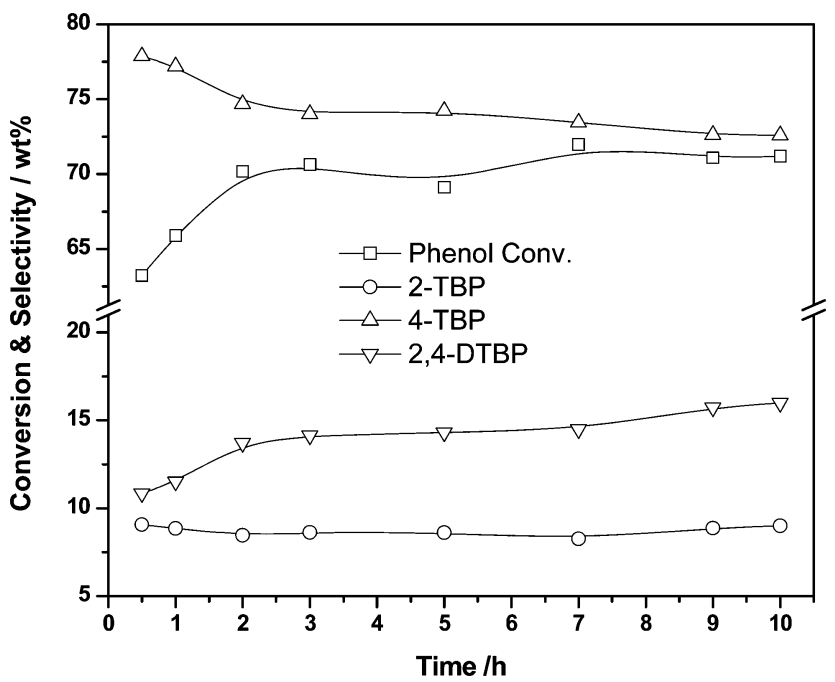

Fig. 5 Al-TUD-1 with $\mathrm{Si} / \mathrm{Al}=25$ is very stable in the gas phase FriedelCrafts alkylation of phenol at $175{ }^{\circ} \mathrm{C}$ and WHSV of $1 \mathrm{~h}^{-1}$. Reprinted from ref. 35. Copyright (2006) with permission from Elsevier.

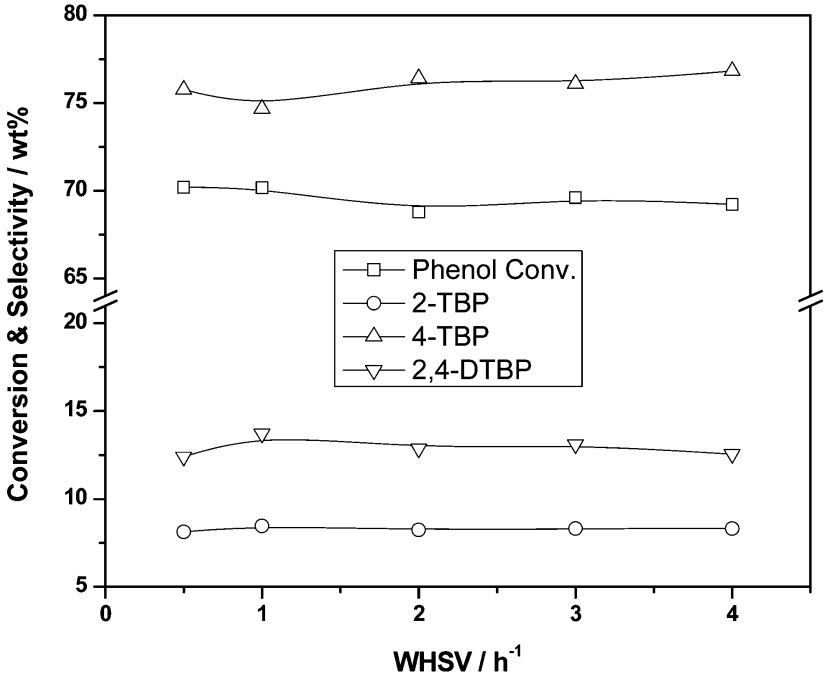

Fig. 6 Al-TUD-1 with $\mathrm{Si} / \mathrm{Al}=25$ is not diffusion limited as is demonstrated by unaltered conversions up to WHSV of $4 \mathrm{~h}^{-1}$. Reprinted from ref. 35. Copyright (2006) with permission from Elsevier.

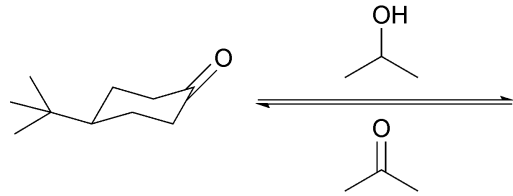

Scheme 4 The Meerwein-Ponndorf-Verley reduction of 4-tert-butyl cyclohexanone yields both, the cis and the trans alcohol.

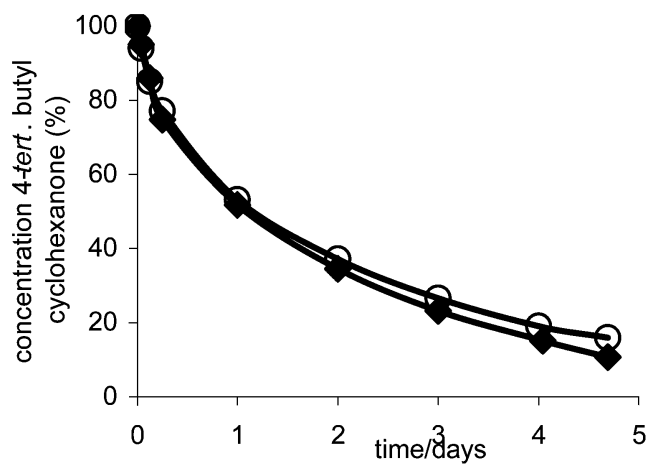

Fig. 7 Recycling of Zr-TUD-1 with $\mathrm{Si} / \mathrm{Zr}=25$ in the MeerweinPonndorf-Verley reduction of 4-tert-butyl cyclohexanone; $\downarrow$ first run; $\bigcirc$ recycled catalyst. Reprinted from ref. 42. Copyright (2006) with permission from Elsevier.

Al-TUD-1 and pure Zr-TUD-1 are both relatively weak catalysts, while all Al-Zr-TUD-1 catalysts perform better (Fig. 10). This, although the metal concentration in all five catalysts is the same, clearly proves the existence of synergy between both types of acid sites. ${ }^{47} \mathrm{~A}$ similar study but with heterogeneous inorganic fluorides as catalysts, was published shortly afterwards. ${ }^{50}$ Again the Prins reaction of citronellal served as the test reaction, confirming the observations made with TUD-1. 


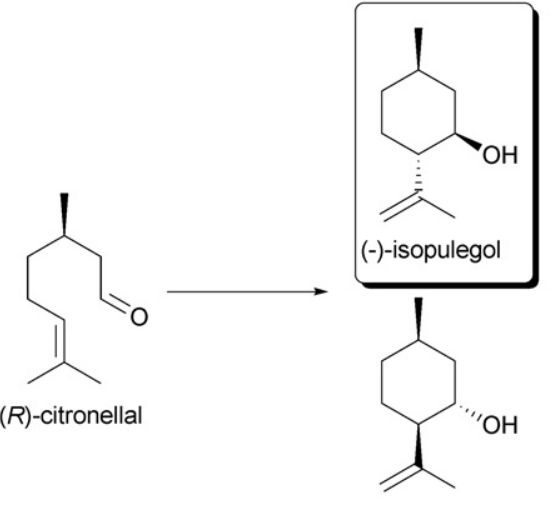

(+)-iso-isopulegol

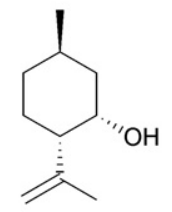

(+)-neo-isopulegol

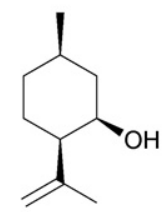

(+)-neoiso-isopulegol
Scheme 5 The acid catalysed Prins reaction of citronellal is employed industrially for the production of isopulegol. The other stereoisomers of isopulegol occur as minor side products.

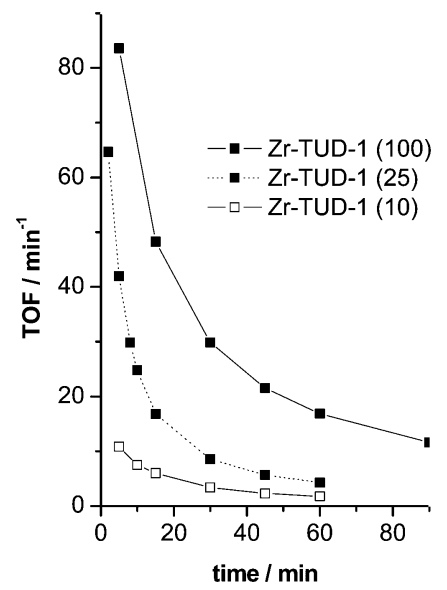

Fig. 8 Prins reaction of industrial grade citronellal catalysed by $\mathrm{Zr}$ TUD-1 with different $\mathrm{Si} / \mathrm{Zr}$ ratios (given in brackets). Reproduced with permission from ref. 43. Copyright 2008, Wiley-VCH Verlag GmbH\&Co. KGaA.

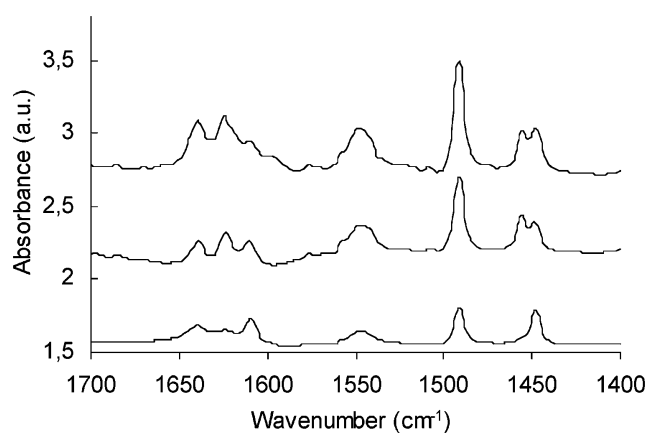

Fig. 9 FT-IR spectra after pyridine desorption at $200{ }^{\circ} \mathrm{C}$. Top: Al-Zr-3:1TUD-1; middle: Al-Zr-2:2-TUD-1; bottom: Al-Zr-1:3-TUD-1. Reproduced by permission of the Royal Society of Chemistry from ref. 47.

3.1.5. Composites of TUD-1 and zeolites. The acidity of zeolites is much stronger than that of mesoporous materials. By incorporation of zeolite nanocrystals inside the mesoporous structure of TUD-1, it was aimed to introduce strong acid sites originating from zeolites. At the same time mass transport limitations associated with zeolites should be greatly reduced due to the large pore diameter and the sponge-like pore character of TUD-1, in combination with the small crystallite size of the incorporated zeolite particles. ${ }^{51,52}$

With XRD as well as HR-TEM it was shown that zeolite nanocrystals of $40 \mathrm{~nm}$ can be homogeneously dispersed throughout the mesoporous TUD-1 matrix. Integrity of mesostructure is retained at values up to $40 \mathrm{wt} \%$ zeolite incorporation. With increased loading of zeolite small aggregates start to emerge, also evidenced by $\mathrm{N}_{2}$ physisorption..$^{27,51}$

FT-IR spectroscopy using either $\mathrm{CO}$ or $\mathrm{NH}_{3}$ has highlighted the modification of acid sites due to interaction of amorphous TUD-1 and the crystalline zeolite particles. In the sample with 40 $\mathrm{w} t \%$ of zeolite the highest concentration of partially extraframework $\mathrm{Al}-\mathrm{OH}$ groups (Brønsted acid sites with medium acidity), as well as distorted siloxane surface bridges that easily can break up in the presence of adsorbates/reactants, have been obtained. At the same time, 40\%-beta-TUD-1, had twice the catalytic activity of pure zeolite beta in $n$-hexane cracking at $538{ }^{\circ} \mathrm{C}$. The abundant presence of both Brønsted sites with medium acidity as well as distorted siloxane bridges might have a synergistic effect during the cracking reactions in the formation/stabilisation of the carbo-cationic intermediates. When comparing the physical mixture of zeolite beta and TUD-1 with $40 \%$-beta-TUD- 1 the higher activity of the composite $40 \%$-betaTUD-1 illustrates the presence of synergy between the catalytic sites (Fig. 11). An alternative explanation would be much better dispersion and thus accessibility of the zeolites in the composite material. ${ }^{51}$

\subsection{Oxidations catalysed by M-TUD-1}

3.2.1. Alkane oxidation. M-TUD-1 materials were studied as catalysts for the oxidation of cyclohexane which is of great industrial importance and a major academic challenge (Scheme 6). ${ }^{53-55}$ As an initial screening of the catalyst, cyclohexane oxidation with tert-butyl hydroperoxide (TBHP) as oxidant revealed that $\mathrm{Co}-\mathrm{Cu}-\mathrm{Cnd} \mathrm{Cr}-\mathrm{TUD}-1$ showed outstanding performances as they decomposed TBHP much faster than other

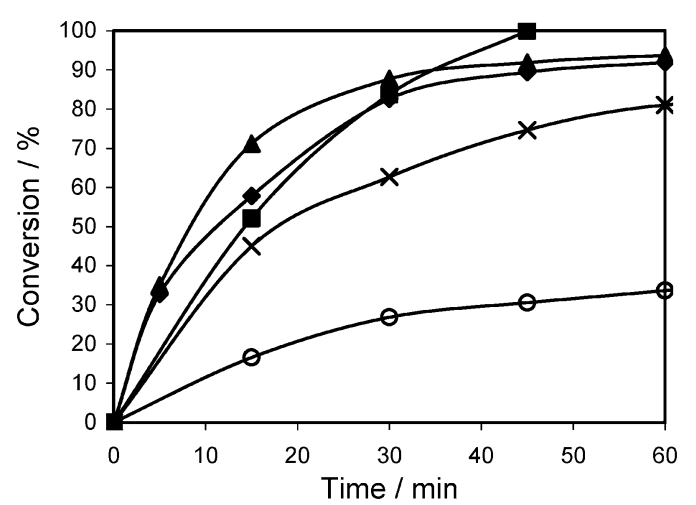

Fig. 10 Prins reaction of citronellal catalysed by Al- and Zr-TUD-1 catalysts with $\mathrm{Si} / \mathrm{M}=25$. Reaction conditions: $4 \mathrm{mmol}$ citronellal, $5 \mathrm{~g}$ toluene, $80^{\circ} \mathrm{C}, 50 \mathrm{mg}$ catalyst. $(\bigcirc) \mathrm{Zr}$-TUD-1 $(\times$ ) Al-TUD-1 ( $)$ Al-Zr1:3-TUD-1 $(\bullet$ Al-Zr-2:2-TUD-1 and $(\boldsymbol{\Delta})$ Al-Zr-3:1-TUD-1. Reproduced by permission of the Royal Society of Chemistry from ref. 47. 


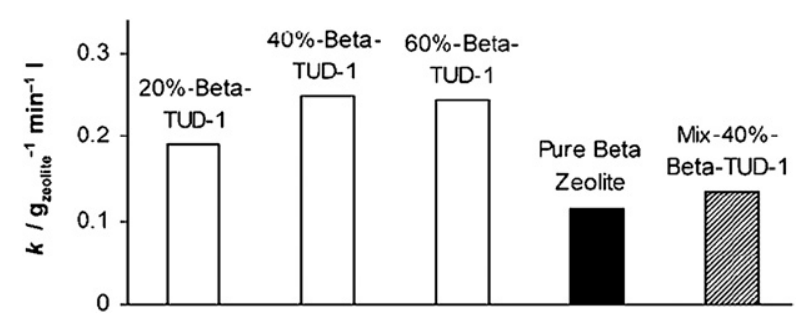

Fig. 11 Composite materials from zeolite beta and TUD-1 display synergy in the catalytic cracking of $n$-hexane. Reproduced with permission from ref. 51. Copyright 2004, Wiley-VCH Verlag GmbH\&Co. KGaA.

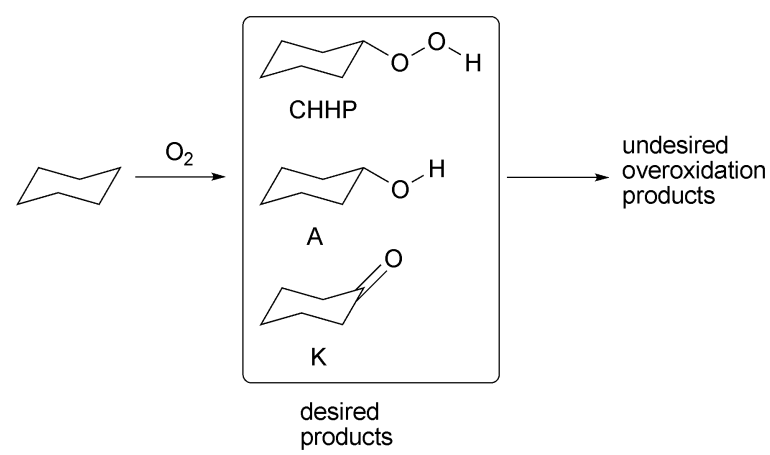

Scheme 6 The selective oxidation of unreactive parafins such as cyclohexane is a veritable challenge since overoxidation of the desired monooxygenated products needs to be avoided.

M-TUD-1's and hence effect the conversion of cyclohexane (Fig. 12) ${ }^{56-58}$ However, a plot of conversion of cyclohexane versus selectivity for mono-oxygenated products displayed a different trend. Cr-, Ti- and Fe-TUD-1 followed a trend similar to the blank reaction. The selectivity decrease is similar to the blank reaction with respect to conversion. $\mathrm{Cu}$ - and Co-TUD-1 showed a very slow decrease even at higher conversion levels of cyclohexane. In particular Co-TUD-1 displayed higher selectivity to mono-oxygenated products for the same cyclohexane conversion as compared to $\mathrm{Cu}-\mathrm{TUD}-1$. Cr-TUD-1 produced more cyclohexanone than cyclohexanol, whereas Co-TUD-1 produced initially more of the alcohol, which was then slowly oxidized to the ketone and the K/A ratio improves. Also hotfiltration experiments and the AAS analysis of the filtrate showed that leaching of $\mathrm{Cr}(13 \%)$ and $\mathrm{Cu}(0.5 \%)$ occurred, whereas the reaction is truly heterogeneous with Co-TUD-1 (Fig. 13). ${ }^{58,59}$

Further studies with different loadings of Co (Fig. 14), revealed that Co-TUD-1 $(\mathrm{Si} / \mathrm{Co}=100)$ with the lowest Co loading, and thus isolated Co atoms (Table 1), displayed the highest activity, directly followed by Co-TUD-1 $(\mathrm{Si} / \mathrm{Co}=50) .{ }^{59}$ In addition to the importance of isolated Co species, this result demonstrates that no diffusion limitation occurs in these mesoporous materials. Co-TUD-1 $(\mathrm{Si} / \mathrm{Co}=20)$ that contain $\mathrm{Co}_{3} \mathrm{O}_{4}$ nanoparticles was observed to be less active, most likely due to the reduced accessibility of the Co atoms. However Co-TUD-1 $(\mathrm{Si} / \mathrm{Co}=10)$ in which bulky Co-oxide clusters are present, showed slightly increased activity, a result in line with the activity of $\mathrm{Co}_{3} \mathrm{O}_{4}$ crystals that have been described earlier. ${ }^{60}$ The observed improvement of the K/A ratio was due to mixed Russell termination between cyclohexyl hydroperoxy radicals and tert-butyl hydroperoxy radicals. ${ }^{61}$ In comparison cyclohexane oxidation catalysed by manganese oxide octahedral molecular sieves showed a turn over number (TON) of 73 in $24 \mathrm{~h}$ at $80^{\circ} \mathrm{C}$ with tert-butyl hydroperoxide as an oxidant and using acetonitrile as solvent, ${ }^{62}$ whereas Co-TUD-1 $(\mathrm{Si} / \mathrm{Co}=100)$ showed a TON of about 100 in $18 \mathrm{~h}$ at $70{ }^{\circ} \mathrm{C}$ which was carried out under solvent-free conditions.

Stimulated by these results this study was extended to the aerobic cyclohexane oxidation, simulating the industrial conditions. M-TUD-1s with $\mathrm{Si} / \mathrm{M}$ ratios of 100 were utilised in the aerobic cyclohexane oxidation (Table 2). ${ }^{63,64}$ With TBHP as initiator, the highest conversions were observed with Co-TUD-1 that also gave the best selectivity toward mono oxygenated products. Cr-TUD-1 was also very active but displayed low selectivity. Ti-TUD-1 and Mn-TUD-1 showed similar activity, with poor selectivity in the case of Mn-TUD-1. Fe-TUD-1 and $\mathrm{Cu}$-TUD-1 were moderately active and thus displayed rather high selectivity, Fe-TUD-1 being somewhat more selective. When TBHP was replaced with cyclohexyl hydroperoxide (CHHP), the initiator commonly employed in industry, Ti-TUD1 lost all its activity, Fe-TUD-1 and also Cu-TUD-1 now displayed low activity, in the case of $\mathrm{Cu}$-TUD-1 coupled with low selectivity (Table 3). ${ }^{63,64}$ Co-TUD-1, Cr-TUD-1 and Mn-TUD-1 were the most active catalysts. In addition Co-TUD-1 exhibits very good selectivity making it the catalyst of choice in this row. Extensive studies of Co-TUD-1 with different $\mathrm{Si} / \mathrm{Co}$ ratios confirmed that Co-TUD-1 with $\mathrm{Si} / \mathrm{Co}=100$ is a very stable, active and selective catalyst for the aerobic cyclohexane oxidation. Mn-TUD-1, on the other hand, combines high activity with very low selectivity. The result for Co-TUD-1 is particular remarkable when placed into a general context. Most of the recent cyclohexane oxidation studies were carried out with molecular oxygen with a pressure of about 5-10 bar. In such a catalytic oxidation over metal ion exchanged ZSM-5 catalysts in a solvent-free system, Co-ZSM-5 showed about $10 \mathrm{~mol} \%$ conversion of cyclohexane and 97\% selectivity for KA-oil. However, the leaching of cobalt from Co-ZSM-5 occurred readily. ${ }^{65}$ Equally Ce-MCM-48 did not perform better than CoTUD-1 in the aerobic oxidation of cyclohexane. ${ }^{66}$

Ti-TUD-1 is a catalyst with excellent selectivity but induces only a little conversion of CHHP. The performance is linked to the titanium loading: low loading yields Ti-TUD-1 with isolated titanium species and ensures the highest observed activity for this metal in CHHP decomposition. High titanium loading leads to extra-framework titanium dioxide particles that are effectively inactive towards CHHP decomposition. In contrast, they are very active in the decomposition of TBHP. In the case of the active, but unselective Mn-TUD-1, higher manganese loadings significantly improved selectivity without loss of activity. Manganese oxide clusters at high manganese loading contain more $\mathrm{Mn}^{3+}$ that improves selectivity. ${ }^{67}$ Comparing all results it is evident, that both metal and $\mathrm{Si} / \mathrm{M}$ ratio are important parameters for the activity of the M-TUD-1 catalysts in the aerobic cyclohexane oxidation. In particular the fact whether the metal is completely incorporated into the silica framework or is present as metal oxide clusters can greatly influence the activity and selectivity of the catalyst. Consequently, the relative fraction of 

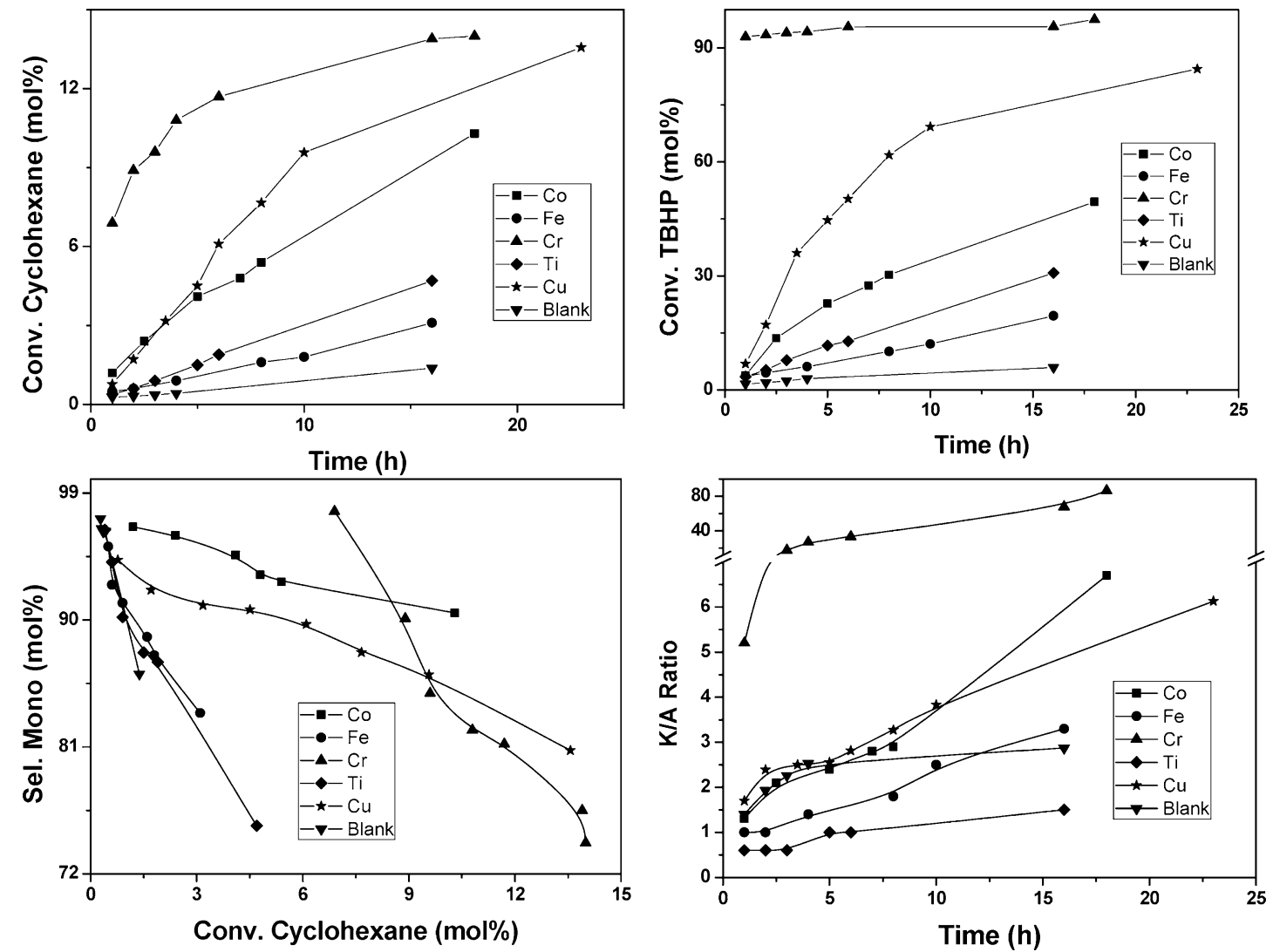

Fig. 12 M-TUD-1 catalysed cyclohexane oxidation with TBHP as sacrificial oxidant.
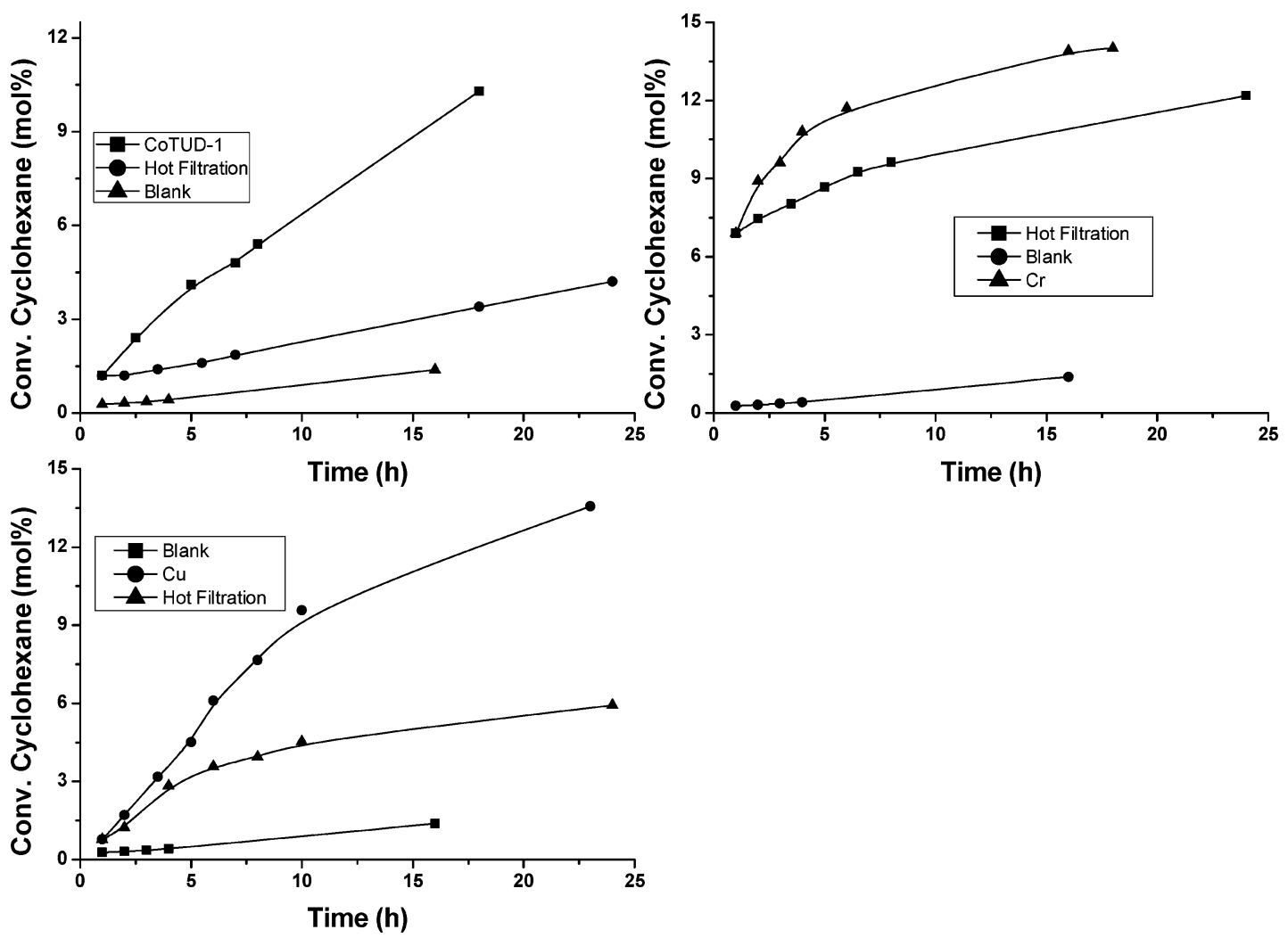

Fig. 13 Hot filtration studies of several M-TUD-1 catalysts reveal that Co-TUD-1 is stable and that no cobalt and consequently no activity leaches. 


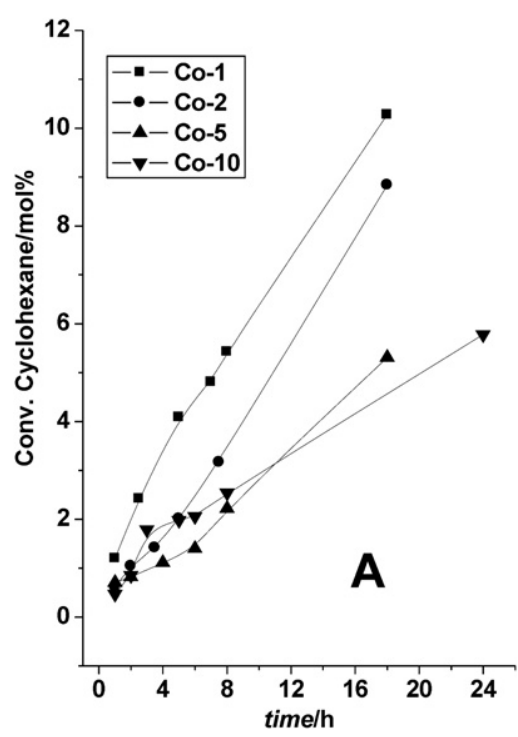

Fig. 14 Co-TUD-1 catalysed oxidation of cyclohexane with TBHP as oxidant. Co-TUD-1 with different $\mathrm{Si} / \mathrm{Co}$ ratios were employed, $\mathrm{Co}-1: \mathrm{Si} /$ $\mathrm{Co}=100, \mathrm{Co}-2: \mathrm{Si} / \mathrm{Co}=50, \mathrm{Co}-5: \mathrm{Si} / \mathrm{Co}=20$ and $\mathrm{Co}-10: \mathrm{Si} / \mathrm{Co}=10$. Reproduced with permission from ref. 59. Copyright 2006, Wiley-VCH Verlag GmbH\&Co. KGaA.

framework-incorporated and extra-framework metal sites may offer a tool for improving the activity and directing the selectivity of M-TUD-1 catalysts for selective oxidation reactions.

In a completely different line of alkane oxidations Fe-TUD-1 and Fe-Al-TUD-1 were utilised as catalysts for the $\mathrm{N}_{2} \mathrm{O}$ mediated oxidation of propane to propene. While both catalysts were less active than $\mathrm{Fe}-\mathrm{AlPO}_{4}-5$ or Fe-ZSM-5, their stability was significantly better, confirming that TUD-1 is a particularly robust material. ${ }^{68}$

3.2.2. Epoxidation of alkenes. Titanium-based catalysts have repeatedly proven their value in the epoxidation of alkenes. To investigate whether the pore structure of TUD-1 offers the expected advantages, i.e. a diffusion limitation free catalytic system, Ti-TUD-1 was compared with Ti-MCM-41. In both samples the titanium was framework incorporated. Ti-TUD-1 displayed a five-times higher TOF in the epoxidation of cyclohexene than Ti-MCM-41. Even after boiling Ti-TUD-1 in water the TOF was still more than four-times higher, giving solid evidence for the stability of the catalyst. ${ }^{11,69}$

As explained in Section 3.2.1. Ti-TUD-1 catalyses the decomposition of TBHP, the reagent used for the epoxidation of the alkenes. Here this decomposition is an undesired side reaction. In order to reduce this rate, the Ti-TUD-1 was silylated, capping acidic silanol and $\mathrm{Ti}-\mathrm{OH}$ groups. This approach was indeed successful, and the silylated Ti-TUD-1 displayed higher selectivity in the epoxidation of 1 -octene. ${ }^{70}$

Very recently the application of Co-TUD-1 for the epoxidation of stilbene using oxygen was described. ${ }^{71}$ At low Co loadings when all the Co is framework incorporated the highest selectivity for epoxidation combined with excellent TOF was observed. Co-TUD-1 outperformed Co-MCM-41, CoX faujasite zeolite and $\mathrm{Co}_{3} \mathrm{O}_{4}$ crystals, it could be recycled for four-times without significant loss of activity and no leaching of the active metal was detected (Scheme 7).

\subsection{Photo-catalysis with M-TUD-1}

Photo-catalysis is another field where TUD-1 based materials have been successfully employed. Photo-catalysis implies the acceleration of a photon induced reaction by the presence of a catalyst. ${ }^{72-74}$ The emphasis of the investigations of M-TUD-1 for this type of catalysis was on the enhancement of the level of understanding of selective photo-oxidation of alkanes. The benefit of the TUD-1 based systems as compared to other silica based supports, lies mainly in the formation of well dispersed active phases up to a loading of approximately $5 \mathrm{wt} \%$ for group $\mathrm{V}$ and group VI elements (Table 1). This is normally difficult to achieve with commercially available silica, or other micro-, or mesoporous materials, and allows one to obtain relatively high signals of isolated active catalytic sites and interactions thereof with reacting species in spectroscopic investigations, even in short time scales and in transient studies. Furthermore, at high loading (10-60 $\left.\mathrm{wt}^{\%} \%\right)$, the synthesis procedure of TUD-1 allows a high level of control of the pore structure and nanoparticle size distribution for some metal oxides (Fig 1), ideal to investigate (nano)particle size effects in photo-catalysis. Three metal oxides dispersed in TUD-1 have been mainly used in the investigation of

Table 2 Aerobic oxidation of cyclohexane over M-TUD-1 (Si/M = 100) in the presence of TBHP as radical initiator. ${ }^{a}$

\begin{tabular}{|c|c|c|c|c|c|c|c|}
\hline M-TUD-1 & & \multicolumn{6}{|l|}{$\mathrm{Mol} \%$} \\
\hline & $\mathrm{Si} / \mathrm{Ti}=50$ & 2.4 & 42.4 & 38.6 & 87.2 & 1.1 & 2.4 \\
\hline & $\mathrm{Si} / \mathrm{Ti}=20$ & 3.4 & 48.5 & 33.7 & 85.6 & 1.4 & 3.4 \\
\hline & $\mathrm{Si} / \mathrm{Ti}=10$ & 3.7 & 54.9 & 23.7 & 81.2 & 2.4 & 3.7 \\
\hline $\mathrm{Cr}$ & & 3.2 & 48.2 & 19.9 & 6.6 & 78.3 & 2.4 \\
\hline $\mathrm{Cu}$ & & 2.6 & 42.1 & 42.8 & 1.4 & 88.8 & 1.0 \\
\hline $\mathrm{Mn}$ & & 2.9 & 26.6 & 52.3 & 3.4 & 85.5 & 0.5 \\
\hline Blank & & 1.3 & 29.5 & 25.8 & 6.5 & 67.7 & 1.1 \\
\hline
\end{tabular}

${ }^{a}$ Conditions: cyclohexane $=175 \mathrm{mmol}$; TBHP $=0.05 \mathrm{mmol} ; \mathrm{PhCl}=1 \mathrm{~g}$ (internal standard); $\mathrm{T}=120{ }^{\circ} \mathrm{C}$; catalyst $=0.1 \mathrm{mmol}$ of active metal species.

${ }^{b}$ Conversion. ${ }^{c}$ Ketone. ${ }^{d}$ Alcohol. ${ }^{e}$ Cyclohexyl hydroperoxide. ${ }^{f}$ Selectivity for mono-oxygenated products. 
Table 3 Aerobic oxidation of cyclohexane over M-TUD-1 $(\mathrm{Si} / \mathrm{M}=100)$ in the presence of CHHP as radical initiator. ${ }^{a}$

\begin{tabular}{|c|c|c|c|c|c|c|c|}
\hline M-TUD-1 & & \multicolumn{6}{|l|}{$\mathrm{Mol} \%$} \\
\hline $\mathrm{Ti}$ & & 0.5 & 24.9 & 43.0 & 12.7 & 91.5 & 0.6 \\
\hline $\mathrm{Cr}$ & & 3.6 & 64.5 & 8.3 & 0.2 & 75.7 & 7.7 \\
\hline \multirow[t]{3}{*}{$\mathrm{Co}$} & $\mathrm{Si} / \mathrm{Co}=100$ & 3.8 & 30.8 & 56.5 & 0.5 & 90.4 & 0.5 \\
\hline & $\mathrm{Si} / \mathrm{Co}=50$ & 3.8 & 58.4 & 31.1 & 1.1 & 91.9 & 1.9 \\
\hline & $\mathrm{Si} / \mathrm{Co}=20$ & 3.0 & 68.2 & 20.8 & 1.0 & 92.7 & 3.3 \\
\hline $\mathrm{Cu}$ & & 2.2 & 43.5 & 34.5 & 2.2 & 82.9 & 1.3 \\
\hline \multirow[t]{4}{*}{$\mathrm{Mn}$} & $\mathrm{Si} / \mathrm{Mn}=100$ & 3.1 & 21.2 & 36.2 & 61.8 & 0.6 & 3.1 \\
\hline & $\mathrm{Si} / \mathrm{Mn}=50$ & 2.2 & 21.1 & 41.9 & 65.3 & 0.5 & 2.2 \\
\hline & $\mathrm{Si} / \mathrm{Mn}=20$ & 2.1 & 24.2 & 47.9 & 74.7 & 0.5 & 2.1 \\
\hline & $\mathrm{Si} / \mathrm{Mn}=10$ & 4.0 & 23.3 & 49.9 & 78.6 & 0.5 & 4.0 \\
\hline \multicolumn{2}{|c|}{ Blank } & 0.6 & 49.3 & 39.0 & 3.2 & 93.0 & 1.2 \\
\hline
\end{tabular}

${ }^{a}$ Conditions: cyclohexane $=175 \mathrm{mmol} ; \mathrm{CHHP}=0.05 \mathrm{mmol} ; \mathrm{PhCl}=1 \mathrm{~g}$ (internal standard); $\mathrm{T}=120{ }^{\circ} \mathrm{C}$; catalyst $=0.1 \mathrm{mmol}$ of active metal species. ${ }^{b}$ Conversion. ${ }^{c}$ Ketone. ${ }^{d}$ Alcohol. ${ }^{e}$ Cyclohexyl hydroperoxide. ${ }^{f}$ Selectivity to mono-oxygenated products.

selective photo-oxidation, i.e. Cr-TUD-1, V-TUD-1 and TiTUD-1.

3.3.1. Cr-TUD-1. Cr-based photo-catalysts were reported in the literature to be highly active in selective photo-oxidation. ${ }^{75} \mathrm{~A}$ TUD- 1 catalyst with $10 \% \mathrm{Cr}$ was used to resolve whether isolated sites are the only active sites, or whether nanoparticles and crystals contribute (Table 1). Structural information was obtained by testing the performance of the highly loaded catalyst with different wavelengths of activation. By careful analysis of the UV-Vis absorption spectrum of the Cr-TUD-1 catalyst, it was established that the $\mathrm{Cr}$ (III) contributions to photo-activity, if any, were to be expected in the wavelength range of 550-650 $\mathrm{nm}$, while $\mathrm{Cr}(\mathrm{VI})$ contributions were to be expected at wavelengths in the range of $300-550 \mathrm{~nm}$. By careful evaluation of the performance of the Cr-TUD-1, using IR spectroscopy to analyse the intrinsic surface adsorbed products, a correlation was established between the wavelength of activation and the photocatalytic performance. ${ }^{76,77}$ A clear maximum in the photoactivity was observed at around $460 \mathrm{~nm}$. At this wavelength isolated $\mathrm{Cr}(\mathrm{VI})$ oxides in a tetrahedral coordination are known to absorb, and therefore this is concluded to be the most active site in the materials. It is remarkable that lower wavelengths of higher energy do not induce higher reactivity. This is the consequence of the quick relaxation of states excited at these smaller wavelengths, leading to the same relatively long lived $\mathrm{Cr}$ (VI) triplet state. Together with the absence of a strong selectivity effect of either wavelength or the absence or presence of oxygen in the feed, reaction occurs between the partially

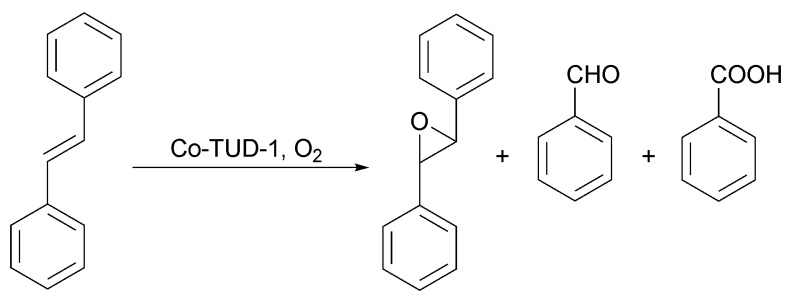

Scheme 7 The selective epoxidation of stilbene is effectively catalysed by Co-TUD-1. High selectivity is observed and little over oxidation occurs. relaxed excited chromophore and an adsorbed propane molecule. Cr(III) species did not contribute to photo-activity, whereby light absorbed by these species was being wasted, inducing lower quantum efficiencies than observed for the $\mathrm{Cr}$ sample with $1 \mathrm{wt}^{\%} \%$. In conclusion, the study suggests that if a high dispersion of $\mathrm{Cr}$ species can be combined with a high loading, the performance per gram of catalyst can be improved. Indeed TUD-1 catalysts with less $\mathrm{Cr} 1-5 \mathrm{wt} \%$ (Table 1 ) show excellent performance in photo-catalytic propane oxidations. ${ }^{76,77}$

3.3.2. V-TUD-1. Silica supported vanadium oxides are effective photo-catalysts in selective hydrocarbon oxidation, typically in gas phase applications. ${ }^{78-80}$ The active vanadia sites are completely dehydrated during the reaction and, without promoters, UV radiation is required to photo-activate the catalytic centres. ${ }^{78-80}$ Hydration results in a shift of the absorption spectrum to the visible, and would in principle generate sites that can be activated by visible light. To further elucidate the structure of the vanadate site during photo-catalysis, and to confirm visible light activity of hydrated sites, vanadia was incorporated in the mesoporous material TUD-1 with a loading of $2 \mathrm{wt} \%$ vanadia, assuring that all vanadia is present as isolated sites (Table 1). The performance in the selective photo-oxidation of liquid cyclohexene was investigated using ATR-FT-IR spectroscopy. ${ }^{81}$ Under continuous illumination at $458 \mathrm{~nm}$ a significant amount of product, i.e. cyclohexenone, was identified. This demonstrated for the first time that indeed hydroxylated vanadia centres in TUD-1 can be activated by visible light to induce oxidation reactions. In view of the spectroscopic evidence, the active site was shown to contain at least one hydroxyl group. Using the rapid scan method, a strong perturbation of the vanadyl environment could be observed in the selective oxidation process induced by a $458 \mathrm{~nm}$ laser pulse of $480 \mathrm{~ms}$ duration. This is proposed to be caused by an interaction of the catalytic centre with a cyclohexenyl hydroperoxide intermediate. Molecular rearrangement and dissociation of the peroxide to ketone and water, led to the restoration of the vanadyl site. The use of V-TUD-1 was instrumental to arrive at the conclusions of the study, because of the well defined structure of the active site. ${ }^{81}$ 
3.3.3. Ti-TUD-1. A strategy to influence the photo-catalytic performance of $\mathrm{TiO}_{2}$, is to support $\mathrm{TiO}_{2}$ on inert $\mathrm{SiO}_{2}$ based materials. One creates isolated molecular Ti sites in tetrahedral coordination, by impregnating mesoporous materials (such as MCM $41^{82-84}$ and SBA-15 $5^{85,86}$ ) with $\mathrm{TiO}_{2}$ precursors. In these procedures, besides isolated sites, clustered $\mathrm{Ti}$ sites are often produced if the loading is increased above $\sim 1-2 \mathrm{wt} \%$. The relative contribution of these clustered sites and/or nanoparticles to the overall photoactivity of $\mathrm{TiO}_{2}$ supported on $\mathrm{SiO}_{2}$ based materials, was typically not considered. The studies involving TUD-1 were thus focused on this aspect. ${ }^{87}$ By varying the crystallization time (Ti-TUD-1 $\mathrm{Si} / \mathrm{Ti}=2.5 ; 8 \mathrm{~h}$ and Ti-TUD-1 Si/Ti $=2.5 ; 24 \mathrm{~h}$, Table 1) two samples were obtained with well defined different nanoparticle sizes (Fig. 15). The pore structure itself is obscured by the depth of field in the HR-TEM images shown in Fig. 15, but the $\mathrm{TiO}_{2}$ crystals in the anatase phase can be identified by their electron diffraction fringes. The typical size of these inclusions corresponds well to the pore diameter obtained from the adsorption isotherms.

To compare the photo-catalytic performance of these materials, the photo-oxidation of propane to acetone (desired), carboxylates (undesired), and water (unavoidable) was analysed with infrared spectroscopy. A narrow width activation of the chromophores $(335 \mathrm{~nm})$ was applied, selectively activating the nanoparticles and excluding possible contributions to the reaction of isolated Ti-centres. Without showing all the spectra, the initial reaction rate is greater in sample Ti-TUD-1 Si/Ti $=2.524$ $\mathrm{h}$ (7.5 $\mathrm{nm}$ particles), yet its activity decreases sharply within the first hour (Fig. 16). For sample Ti-TUD-1 Si/Ti $=2.58 \mathrm{~h}(3.5 \mathrm{~nm}$ particles) a lower initial rate is observed, by a factor of 4.8 , but this rate is maintained over a prolonged period of time. At all stages of product accumulation the selectivity towards acetone of the Ti-TUD-1 $\mathrm{Si} / \mathrm{Ti}=2.58 \mathrm{~h}$ sample $(3.5 \mathrm{~nm})$ is approximately $50 \%$ greater than that of Ti-TUD-1 Si $/ \mathrm{Ti}=2.524 \mathrm{~h}(7.5 \mathrm{~nm})$, as shown in Fig. 16. These results show that the particles formed at a higher loading in mesoporous materials contribute to photocatalytic activity to a significant extent, while the selectivity of oxidation products seems to be larger, the smaller the particles are. Further studies are underway using these well-defined Ti-TUD-1 materials in combination with fluorescence studies, to better understand the observed differences. Furthermore Ti-TUD-1 will be evaluated in the photo-activation of $\mathrm{CO}_{2}{ }^{88-90}$

\section{TUD-1 as catalyst-carrier}

In addition to its catalytic activity TUD-1 can also act as a catalyst carrier. Al-TUD-1 with a Si/Al ratio of 4 is a Brønsted acid that can function as an ion exchanger for the ionic immobilisation of transition metal catalysts, a particularly attractive way to immobilise catalysts as the catalyst does not have to be modified. ${ }^{20,91,92}$ Due to its three-dimensional, sponge-like pore structure with large mesopores Al-TUD-1 can easily host these catalysts. The immobilised catalysts remain accessible and since they are inside the pore system of Al-TUD-1, they should be compartmentalised and protected against deactivation.

When immobilising catalysts care has to be taken that the catalyst does not loose activity or selectivity. Furthermore the immobilisation method has to be straightforward. This is indeed the case with Al-TUD-1 as a carrier. Asymmetric hydrogenation catalysts based on different rhodium(I) complexes were immobilised via ion-exchange. They maintained their activity and selectivity, however some leaching of the metal was observed. ${ }^{20}$ When $\left[\mathrm{Rh}(\mathrm{MonoPHOS})_{2}(\mathrm{cod}) \mathrm{BF}_{4}\right.$ was immobilised on $\mathrm{Al}-$ TUD-1 it not only retained activity and selectivity, it could be applied in water (Scheme 8); a solvent otherwise not suitable for this catalyst, ${ }^{93}$ adding a significant environmental advantage to
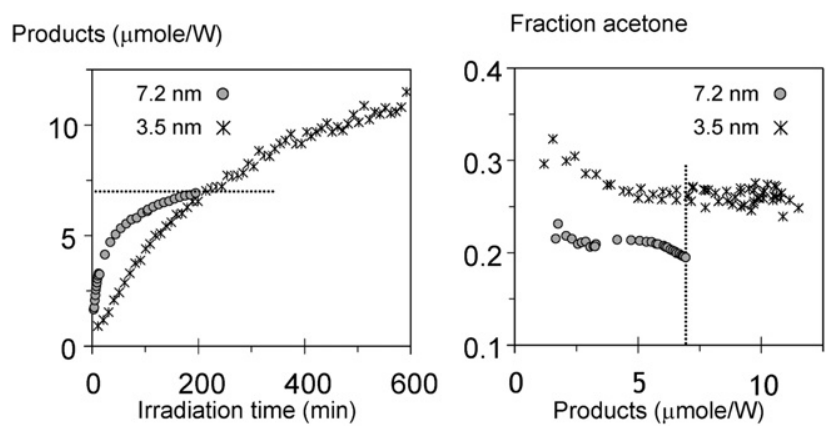

Fig. 16 Left panel: molar sum of adsorbed products (acetone+water+carboxylates) produced as a function of time over two Ti-TUD-1 with $\mathrm{Si} / \mathrm{Ti}=2.5(\mathrm{Ti}-40)$ samples. The initial slope, or reaction rate, is greater in the large-particle sample. Right panel: molar fraction of acetone as a function of the molar sum of adsorbed products. The $8 \mathrm{~h}$ sample, containing smaller $\mathrm{TiO}_{2}$ crystals, yields a larger fraction of acetone - as is directly evident from the spectra.
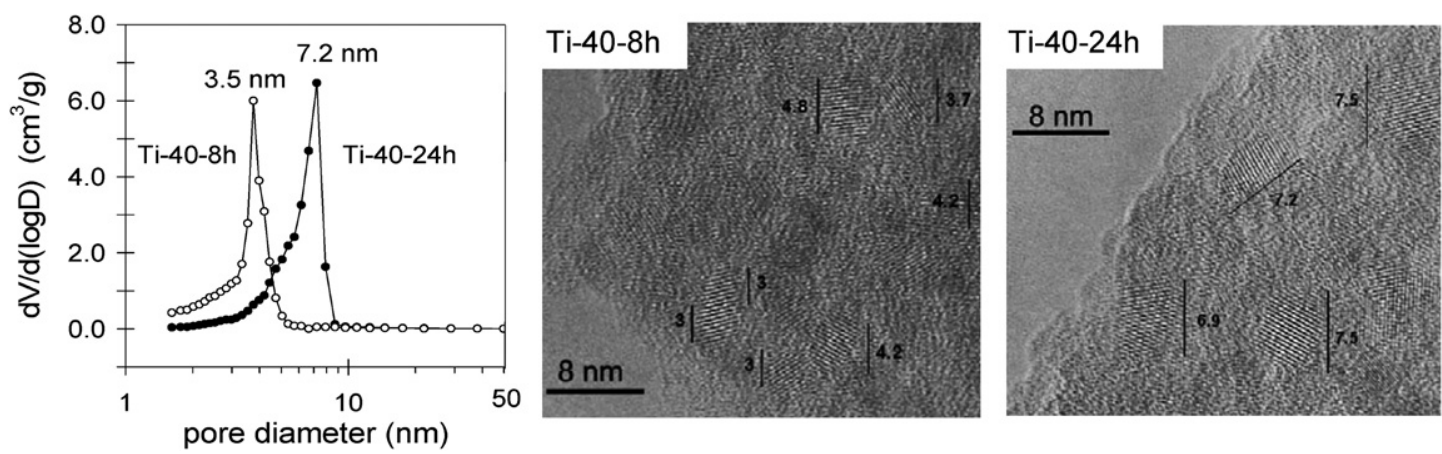

Fig. 15 Left: pore size distributions of the Ti-TUD-1 with $\mathrm{Si} / \mathrm{Ti}=2.5(\mathrm{Ti}-40)$ samples after $8 \mathrm{~h}$ and 24 h hydrothermal treatment, as obtained from the isotherms. Center and right: transmission electron micrographs of the corresponding samples. The structure of individual pores is not visible, but titania crystallites can be identified by their electron-diffraction fringes. Size estimates are indicated in $\mathrm{nm}$. 

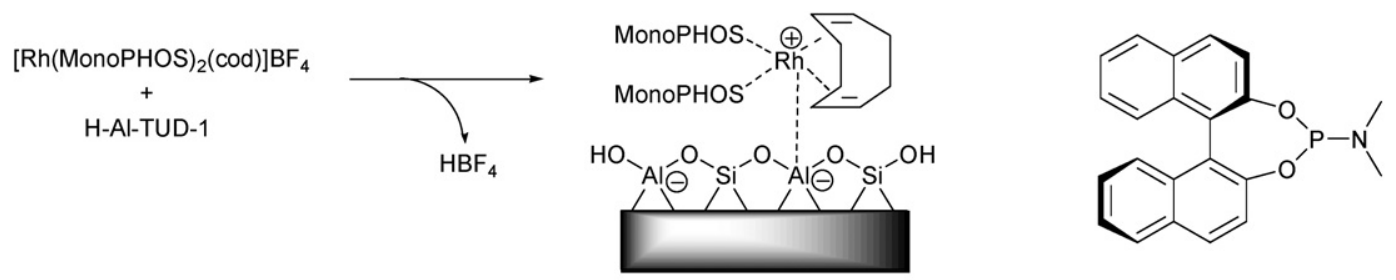

(R)-MonoPHOS
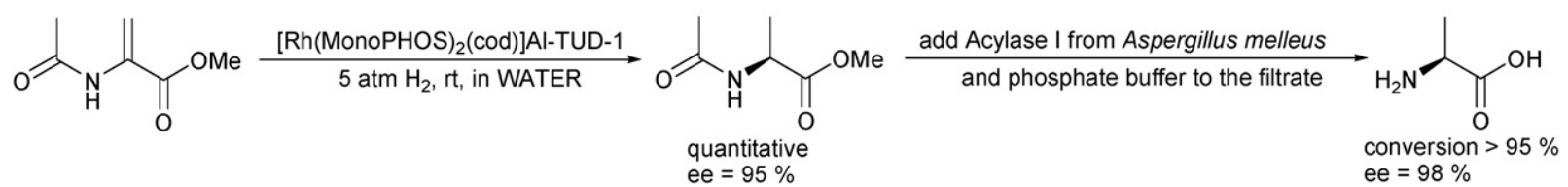

Scheme 8 Straightforward ion exchange enables the robust immobilisation of rhodium-based enantioselective hydrogenation catalysts. Due to the immobilisation the catalyst can be applied in water, facilitating a cascade of reactions, leading to enantiopure alanine.

this catalyst. ${ }^{94}$ Furthermore, it could be recycled several times, demonstrating the versatility of this immobilisation.

The immobilised $\left[\mathrm{Rh}(\text { MonoPHOS })_{2}(\operatorname{cod})\right]$ was used for the enantioselective reduction of methyl-2-acetamidoacrylate in water. Subsequent filtration and addition of Acylase I allowed the deprotection of the intermediate, yielding enantiopure L-alanine (Scheme 8). Thus Al-TUD-1 as a carrier enables a cascade of two catalytic reactions for the clean and environmentally benign synthesis of chiral amino acids. ${ }^{95}$

To further improve the immobilisation $\mathrm{Al}_{2} \mathrm{O}_{3}$-TUD-1 was also studied as a carrier. When the catalyst was immobilised in the presence of phosphotungstic acid, a heteropoly acid, it was even better protected against leaching than on Al-TUD-1. ${ }^{16}$

\section{TUD-1 as material}

The applications in chemistry have proven that TUD-1 is a very versatile material. In addition to these more classical utilisations of a mesoporous material, TUD-1 has also been used because of its properties as a material. In medicinal research TUD-1 was investigated as a magnetic resonance imaging (MRI) contrast agent. Protic Al-TUD-1 ( $\mathrm{Si} / \mathrm{Al}=3.5)$ was ion exchanged against gadolinium as $\mathrm{Gd}^{3+}$. The MRI parameters of $\mathrm{Gd}^{3+}$ Al-TUD-1 were tested in the laboratory; however, while its MRI properties were good, the gadolinium leached rapidly. ${ }^{96}$ Since gadolinium is highly toxic, this rules out any practical application of $\mathrm{Gd}^{3+}$ Al-TUD-1 as a MRI reagent at the current stage of development.

Due to its large surface area and mesoporous, sponge-like character TUD-1 was tested as a drug delivery system. Siliceous TUD-1 took up $49.5 \mathrm{wt} \%$ ibuprofen, thus one third of the loaded TUD-1 was ibuprofen. Importantly the ibuprofen could be released rapidly from the TUD-1. Within $15 \mathrm{~min} 60 \%$ was liberated and after $210 \min 96 \%$ of the drug had left the carrier. This makes TUD-1 a good candidate as a drug carrier for poorly soluble drugs..$^{97,98}$

\section{Conclusions and outlook}

A decade after its first description TUD-1 is firmly established as a versatile mesoporous material. Its straightforward, scalable and predictable synthesis allows successful preparation of TUD1 and M-TUD-1 without special knowledge. Its application in catalysis has revealed that M-TUD-1s are highly applicable catalysts even in such demanding reactions as the oxidation of cyclohexane. The high stability of TUD-1 also ensures its application in medicinal research and as a carrier of homogeneous catalysts. Additionally, it enabled fundamental insights into the operation of photo-catalysts.

Based on the results achieved within a decade it is obvious that the utilisation of TUD-1 in all its variations is but at the beginning. Indeed, molecularly designed multi-component nanostructures in molecular sieves have a high potential in photo-catalytic conversions using visible light. Novel avenues are the synthesis and evaluation of multi-component nanostructures in TUD-1, creating ideal materials for photo catalytic studies. Similar to the immobilisation of chemical catalysts, enzymes might be fixated into the pores of TUD-1, or immobilised chemical catalysts might be used in concert with the catalytic properties of their carrier, achieving cascade reactions. Co-TUD-1 is expected to function as an anchor for enzymes with a histidine-tag. ${ }^{9}$ These enzymes might then convert the oxidation products prepared with Co-TUD-1 as a catalyst. This would enable entirely new routes to esters, diols and chiral alcohols. Equally it might be envisaged that the enzyme immobilised inside the pores of a M-TUD-1 can catalyse the release of a drug from a pro drug and thus help to establish advanced drug delivery systems. As the very different applications in medicinal research demonstrate, it is only imagination that limits the future of TUD-1.

\section{Acknowledgements}

The authors gratefully acknowledge the inventors of TUD-1 for introducing them into this interesting field of research. S. T. thanks NWO (Mozaik fellowship) for financial support. M. S. Hamdy and O. Berg have significantly contributed to the paragraphs describing the evaluation of the photocatalytic performance of TUD-1 catalysts.

\section{References}

1 Y. Wan and D. Zhao, Chem. Rev., 2007, 107, 2821-2860.

2 J. C. Jansen, Z. Shan, L. Marchese, W. Zhou, N. v. d. Puil and T. Maschmeyer, Chem. Commun., 2001, 713-714. 
3 X. S. Zhao, F. Su, Q. Yan, W. Guo, X. Y. Bao, L. Lv and Z. Zhou, J. Mater. Chem., 2006, 16, 637-648.

4 J. G. Verkade, Acc. Chem. Res., 1993, 26, 483-489.

5 A. Singh and R. C. Mehrotra, Coord. Chem. Rev., 2004, 248, 101-118.

6 S. Cabrera, J. El Haskouri, C. Guillem, J. Latorre, A. Beltran-Porter, D. Beltran-Porter, M. Dolores Marcos and P. Amoros, Solid State Sci., 2000, 2, 405-420.

7 D. Ortiz de Zárate, A. Gómez-Moratalla, C. Guillem, A. Beltrán, J. Latorre, D. Beltrán and P. Amorós, Eur. J. Inorg. Chem., 2006, 2572-2581

8 J. El Haskouri, S. Cabrera, C. Guillem, J. Latorre, A. Beltran, D. Beltran, M. Dolores Marcos and P. Amoros, Chem. Mater., 2002, 14, 5015-5022.

9 J. El Haskouri, J. M. Morales, D. Ortiz de Zarate, L. Fernandez, J. Latorre, C. Guillem, A. Beltran, D. Beltran and P. Amoros, Inorg. Chem., 2008, 47, 8267-8277.

10 D. Ortiz de Zárate, L. Fernandez, A. Beltran, C. Guillem, J. Latorre, D. Beltran and P. Amoros, Solid State Sci., 2008, 10, 587-601.

11 Z. Shan, E. Gianotti, J. C. Jansen, J. A. Peters, L. Marchese and T. Maschmeyer, Chem.-Eur. J., 2001, 7, 1437-1443.

12 A. C. Pierre, Biocatal. Biotransform., 2004, 22, 145-170.

13 R. K. Iler, The Chemistry of Silica, John Wiley \& Sons, New York, Chichester, Bisbane, Toronto, 1979, ch. 5, pp. pp. 462-621.

14 Z. Shan, J. C. Jansen, W. Zhou and T. Maschmeyer, Appl. Catal., A, 2003, 254, 339-343.

15 Z.-X. Zhang, P. Bai, B. Xu and Z.-F. Yan, J. Porous Mater., 2006, 13, 245-250.

16 C. Simons, U. Hanefeld, I. W. C. E. Arends, T. Maschmeyer and R. A. Sheldon, J. Catal., 2006, 239, 212-219.

17 A. M. Gaffney, TUD-1: A generalized mesoporous catalyst family for industrial applications. Abstr. Papers, 235th ACS National Meeting, New Orleans, LA, United States, April 6-10, 2008.

18 A. Gaffney, TUD-1: Advanced catalytic materials for the refining and petrochemical industry. Abstr. Papers, 236th ACS National Meeting, Philadelphia, PA, United States, August 17-21, 2008.

19 Z. Shan, J. C. Jansen, C. Y. Yeh, P. J. Angevine, T. Maschmeyer and M. S. Hamdy, US 2006/0052234 A1.

20 C. Simons, U. Hanefeld, I. W. C. E. Arends, R. A. Sheldon and T. Maschmeyer, Chem.-Eur. J., 2004, 10, 5829-5835.

21 I. C. Neves, G. Botelho, A. V. Machado, P. Rebelo, S. Ramôa, M. F. R. Pereira, A. Ramanathan and P. Pescarmona, Polym. Degrad. Stab., 2007, 92, 1513-1519.

22 A. Tuel, Microporous Mesoporous Mater., 1999, 27, 151-169.

23 Y. Z. Zhu, S. Jaenicke and G.-K. Chuah, J. Catal., 2003, 218, 396-404.

24 K. P. de Jong, A. J. Koster, A. H. Janssen and U. Ziese, Stud. Surf. Sci. Catal., 2005, 157, 225-242.

25 M. S. Hamdy, Ph. D. Thesis, Technische Universiteit Delft, Delft, The Netherlands, 2005, open access on: http://www.library.tudelft.nl/ws/ search/publications/index.htm.

26 C. Aquino and T. Maschmeyer, A New Family of Mesoporous Oxides - Synthesis, Characterisation and Applications of TUD-1. In Ordered Porous Solids, recent advances and Prospects, ed. V. Valtchev, S. Mintova and M. Tsapatsis, Elsevier B.V. 2009, pp. 3-30.

27 P. J. Angevine, A. M. Gaffney, Z. Shan and C. Y. Yeh, Advanced Catalytic Materials for the Refining and Petrochemical Industry: TUD-1, in ACS Symposium Series, 2009, 1000, 335-363.

28 R. A. Sheldon, H. van Bekkum, Fine Chemicals through Heterogeneous Catalysis, Wiley-VCH, Weinheim, 2001.

29 M. S. Hamdy, G. Mul, J. C. Jansen, A. Ebaid, Z. Shan, A. R. Overweg and T. Maschmeyer, Catal. Today, 2005, 100, $255-260$.

30 N. N. Tušar, A. Ristic, S. Cecowski, I. Arcon, K. Lazar, H. Amenitsch and V. Kaucic, Microporous Mesoporous Mater., 2007, 104, 289-295.

31 J. Cao, N. He, C. Li, J. Dong and Q. Xu, Stud. Surf. Sci. Catal., 1998, 117, 461-467.

32 K. Bachari, J. M. M. Millet, B. Benaichouba, O. Cherifi and F. Figueras, J. Catal., 2004, 221, 55-61.

33 V. R. Choudhary, S. K. Jana and B. P. Kiran, Catal. Lett., 1999, 59, 217-219.

34 A. Vinu, D. P. Sawant, K. Ariga, M. Hartmann and S. B. Halligudi, Microporous Mesoporous Mater., 2005, 80, 195-203.

35 R. Anand, R. Maheswari and U. Hanefeld, J. Catal., 2006, 242, $82-91$.
36 E. Modrogan, M. H. Valkenberg and W. F. Hoelderich, J. Catal., 2009, 261, 177-187.

37 A. Sakthivel, S. K. Badamali and P. Selvam, Microporous Mesoporous Mater., 2000, 39, 457-463.

38 P. Selvam and S. E. Dapurkar, Catal. Today, 2004, 96, 135-141.

39 A. Vinu, B. M. Devassy, S. B. Halligudi, W. Böhlmann and Martin Hartmann, Appl. Catal., A, 2005, 281, 207-213.

40 M. Boronat, A. Corma and M. Renz, J. Phys. Chem. B, 2006, 110, 21168-21174.

41 Y. Zhu, G. Chuah and S. Jaenicke, J. Catal., 2004, 227, 1-10.

42 A. Ramanathan, D. Klomp, J. A. Peters and U. Hanefeld, J. Mol. Catal. A: Chem., 2006, 260, 62-69.

43 A. Ramanathan, M. C. C. Villalobos, C. Kwakernaak, S. Telalovic and U. Hanefeld, Chem.-Eur. J., 2008, 14, 961-972.

44 F. Neatu, S. Coman, V. I. Parvulescu, G. Poncelet, D. De Vos and Pierre Jacobs, Top. Catal., 2009, 52, 1292-1300.

45 Y. Nie, S. Jaenicke and G.-K. Chuah, Chem.-Eur. J., 2009, 15, 1991-1999.

46 L. Veum and U. Hanefeld, Chem. Commun., 2006, 825-831.

47 S. Telalovic, J. F. Ng, R. Maheswari, A. Ramanathan, G. K. Chuah and U. Hanefeld, Chem. Commun., 2008, 4631-4633.

48 S. Li, A. Zheng, Y. Su, H. Zhang, L. Chen, J. Yang, C. Ye and F. Deng, J. Am. Chem. Soc., 2007, 129, 11161-11171.

49 P. Kalita, N. M. Gupta and R. Kumar, J. Catal., 2007, 245, 338-347.

50 S. M. Coman, P. Patil, S. Wuttke and E. Kemnitz, Chem. Commun., 2009, 460-462.

51 P. Waller, Z. Shan, L. Marchese, G. Tartaglione, W. Zhou, J. C. Jansen and T. Maschmeyer, Chem.-Eur. J., 2004, 10, 4970-4976.

52 Z. Shan, J. C. Jansen, C. Y. Yeh, J. H. Koegler and T. Maschmeyer, WO 03/045548 A1.

53 M. T. Musser, Cyclohexanol and Cyclohexanone, in Ullmann's Encyclopedia of Industrial Chemistry, electronic edition, Wiley-VCH Verlag, Weinheim, 2005.

54 I. Hermans, J. Peeters and P. A. Jacobs, Top. Catal., 2008, 48, 41-48.

55 J. A. Labinger, J. Mol. Catal. A: Chem., 2004, 220, 27-35.

56 M. S. Hamdy, G. Mul, W. Wei, R. Anand, U. Hanefeld, J. C. Jansen and J. A. Moulijn, Catal. Today, 2005, 110, 264-271.

57 R. Anand, M. S. Hamdy, P. Gkourgkoulas, T. Maschmeyer, J. C. Jansen and U. Hanefeld, Catal. Today, 2006, 117, 279-283.

58 R. Anand, M. S. Hamdy, U. Hanefeld and T. Maschmeyer, Catal. Lett., 2004, 95, 113-117.

59 M. S. Hamdy, A. Ramanathan, T. Maschmeyer, U. Hanefeld and J. C. Jansen, Chem.-Eur. J., 2006, 12, 1782-1789.

60 L. Zhou, J. Xu, H. Miao, F. Wang and X. Li, Appl. Catal., A, 2005, 292, 223-228.

61 M. Nowotny, L. N. Pedersen, U. Hanefeld and T. Maschmeyer, Chem.-Eur. J., 2002, 8, 3724-3731.

62 R. Kumar, S. Sithambaram and S. L. Suib, J. Catal., 2009, 262, 304 313.

63 A. Ramanathan, M. S. Hamdy, R. Parton, Th. Maschmeyer, J. C. Jansen and U. Hanefeld, Appl. Catal., A, 2009, 355, 78-82.

64 R. Anand, M. S. Hamdy, R. Partone, T. Maschmeyer, J. C. Jansen, R. Gläser, F. Kapteijn and U. Hanefeld, Aust. J. Chem., 2009, 62, 360-365.

65 H.-X. Yuan, Q.-H. Xia, H.-J. Zhan, X.-H. Lu and K.-X. Su, Appl. Catal., A, 2006, 304, 178-184.

66 W. Zhan, G. Lu, Y. Guo, Y. Guo, Y. Wang, Y. Wang, Z. Zhang and X. Liu, J. Rare Earths, 2008, 26, 515-522.

67 A. Ramanathan, T. Archipov, R. Maheswari, U. Hanefeld, E. Roduner and R. Gläser, J. Phys. Chem. C, 2008, 112, 7468-7476.

68 W. Wei, J. A. Moulijn and G. Mul, J. Catal., 2009, 262, 1-8.

69 Z. Shan, J. C. Jansen, L. Marchese and T. Maschmeyer, Microporous Mesoporous Mater., 2001, 48, 181-187.

70 M. R. Prasad, M. S. Hamdy, G. Mul, E. Bouwman and E. Drent, J. Catal., 2008, 260, 288-294.

71 X.-Y. Quek, Q. Tang, S. Hu and Y. Yang, Appl. Catal., A, 2009, 361, 130-136.

72 A. Mills and S. LeHunte, J. Photochem. Photobiol., A, 1997, 108, $1-35$.

73 J. M. Herrmann, Top. Catal., 2006, 39, 3-10.

74 O. Carp, C. L. Huisman and A. Reller, Prog. Solid State Chem., 2004, 32, 33-177.

75 H. Yamashita, K. Yoshisawa, M. Ariyuki, S. Higashimoto, M. Che and M. Anpo, Chem. Commun., 2001, 435-436. 
76 O. Berg, M. S. Hamdy, T. Maschmeyer, J. A. Moulijn, M. Bonn and G. Mul, J. Phys. Chem. C, 2008, 112, 5471-5475.

77 M. S. Hamdy, O. Berg, J. C. Jansen, T. Maschmeyer, A. Arafat, J. A. Moulijn and G. Mul, Catal. Today, 2006, 117, 337-342.

78 F. Amano, T. Yamaguchi and T. Tanaka, J. Phys. Chem. B, 2006, 110, 281-288.

79 F. Amano, T. Tanaka and T. Funabiki, Langmuir, 2004, 20, 42364240.

80 S. Takenaka, T. Tanaka, T. Funabiki and S. Yoshida, J. Chem. Soc., Faraday Trans., 1997, 93, 4151-4158.

81 G. Mul, W. Wasylenko, M. S. Hamdy and H. Frei, Phys. Chem. Chem. Phys., 2008, 10, 3131-3137.

82 T. Tanaka, K. Teramura, T. Yamamoto, S. Takenaka, S. Yoshida and T. Funabiki, J. Photochem. Photobiol., A, 2002, 148, 277-281.

83 A. Bhattacharyya, S. Kawi and M. B. Ray, Catal. Today, 2004, 98, 431-439.

84 R. van Grieken, J. Aguado, M. J. Lopez-Munoz and J. Marugan, J. Photochem. Photobiol., A, 2002, 148, 315-322.

85 S. Zheng, L. A. Gao, Q.-H. Zhang and J.-K. Guo, J. Mater. Chem., 2000, 10, 723-727.

86 Z. H. Luan and L. Kevan, Microporous Mesoporous Mater., 2001, 44-45, 337-344.

87 M. S. Hamdy, O. Berg, J. C. Jansen, T. Maschmeyer, J. A. Moulijn and G. Mul, Chem.-Eur. J., 2006, 12, 620-628.

88 J.-S. Hwang, J.-S. Chang, S.-E. Park, K. Ikeue and M. Anpo, Top. Catal., 2005, 35, 311-319.
89 M. Anpo, H. Yamashita, Y. Ichihashi, Y. Fujii and M. Honda, J. Phys. Chem. B, 1997, 101, 2632-2636.

90 M. Anpo, H. Yamashita, K. Ikeue, Y. Fujii, S. G. Zhang, Y. Ichihashi, D. R. Park, Y. Suzuki, K. Koyano and T. Tatsumi, Catal. Today, 1998, 44, 327-332.

91 J. M. Fraile, J. I. Garcia and J. A. Mayoral, Chem. Rev., 2009, 109, 360-417.

92 A. F. Trindade, P. M. P. Gois and C. A. M. Afonso, Chem. Rev, $2009,109,418-514$.

93 C. Simons, U. Hanefeld, I. W. C. E. Arends, A. J. Minnaard, Thomas Maschmeyer and R. A. Sheldon, Chem. Commun., 2004, $2830-2831$.

94 P. Barbaro and F. Liguori, Chem. Rev., 2009, 109, 515-529.

95 C. Simons, U. Hanefeld, I. W. C. E. Arends, T. Maschmeyer and R. A. Sheldon, Adv. Synth. Catal., 2006, 348, 471-475, + 2006, 348, 792.

96 M. Norek, I. C. Neves and Joop A. Peters, Inorg. Chem., 2007, 46, 6190-6196.

97 T. Heikkilä, J. Salonen, J. Tuura, M. S. Hamdy, G. Mul, N. Kumar, T. Salmi, D. Yu. Murzin, L. Laitinen, A. M. Kaukonen, J. Hirvonen and V.-P. Lehto, Int. J. Pharm., 2007, 331, 133-138.

98 T. Heikkilä, J. Salonen, J. Tuura, N. Kumar, T. Salmi, D. Yu. Murzin, M. S. Hamdy, G. Mul, L. Laitinen, A. M. Kaukonen, J. Hirvonen and V.-P. Lehto, Drug Delivery, 2007, 14, 337-347.

99 U. Hanefeld, L. Gardossi and E. Magner, Chem. Soc. Rev., 2009, 38, 453-468. 